$5 c 9$

$$
\begin{gathered}
9 B \\
634.1 \\
K N 1 \\
Q
\end{gathered}
$$




\section{1}

KNI-

$Q$ 





\title{
POMONA HEREFORDIENSIS;
}

CONTAINING

\author{
COLOURED ENGRAVINGS
}

OF THE

\section{OLD GIDER AND PERRY FRUITS}

OF HEREFORDSHIRE.

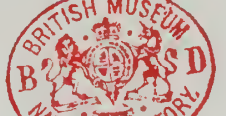

WITH SUCH

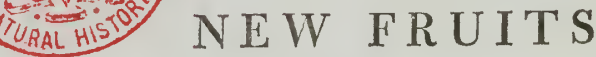

AS HAVE BEEN FOUND TO POSSESS SUPERIOR EXCELLENCE.

ACCOMPANIED WITH

A DESCRIPTIVE ACCOUNT OF EACH VARIETY,

BY THOMAS ANDREW KNIGHT, ESQ.

$$
\text { F. R. S. \& L. S. }
$$

AND PRESIDENT OF THE HORTICULTURAL SOCIETY OF LONDON.

PUBLISHED BY

THE AGRICULTURAL SOCIETY OF HEREFORDSHIRE.

\section{LONDON :}

PRINTED FOR THE AGRICULTURAL SOCIETY OF HEREFORDSHIRE, BY W. BULMER AND CO. CLEVELAND-ROW, ST. JAMES'S; AND SOLD BY W. HOOKER, 75, JOHN STREET, FITZROY-SQUARE; WHITE AND COCHRANE, FLEET-STREET; AND J. HARDING, ST. JAMES'S-STREET. 



\section{PRELIMINARY OBSERVATIONS.}

$\mathbf{I}_{\mathrm{T}}$ had unquestionably been fortunate for mankind if the use of fermented liquors had never been introduced anongst them, and still more fortunate, if the means of concentrating, by distillation, the noxious qualities of those liquors, had remained unknown. But the luxuries and artificial wants of preceding generations, become the necessaries of life amongst those which succeed ; the constitutions of our children become adapted to the acquired habits of their ancestry ; and it may be questioned whether our peasantry, in the aggregate, could now toil through the heats of summer without the aid of fermented liquors, though it must be admitted that these do little more than enable them to borrow, from the future, the stimulus to exertion in the present hour. That the labouring classes will not consent to try the experiment is certain; and whether fermented liquors be necessary, or not, to the peasant, they certainly are so to the farmer, who could not possibly get his corn collected without their aid: and it therefore only remains to be enquired, whether such liquors can be most advantageously obtained from malt alone, or from that partly, and in conjunction with fruit liquors.

The soils, which are best calculated for the growth of barley, are generally unfavourable to that of the apple and pear; and the strong argillaceous loams, in which the apple and pear succeed best, are almost always very ill calculated for the culture of barley. Upon such soils, therefore, fruit liquors can probably be obtained 


\section{[ii ]}

with much advantage; and the high rents which are given for young and healthy orchards, in every part of England, sufficiently prove the value of their produce.

But the success and profits of the planter depend almost wholly upon the proper choice of varieties of fruit, and the selection of these will generally prove a task of much difficulty: for our nomenclature of fruits, of almost every species, is so imperfect and confused, that two or more varieties are generally confounded under one name, and the same variety is as frequently known under many different names: experience appears also to have sufficiently proved that each variety is fit for culture during a limited period only, after it has first sprung from seed; and therefore the sources of error, in the selection of proper fruits, are exceedingly numerous.

With a view to prevent the losses and inconveniences which have arisen from the preceding causes, and from the rapid decay of every old variety of the apple and pear, the Agricultural Society of Herefordshire proposed the publication of coloured Plates of those old varieties to which their county has been indebted for its fame, and also of a few new varieties, which have been introduced under their patronage, and are believed to be not inferior to the old. Written descriptions have proved generally sufficient to enable the botanist to distinguish one original species of plants from another; but coloured Plates alone are capable of pointing out those slight discriminations of character, which often distinguish one variety of fruit from another, of any given species.

The decay of every variety of the apple and pear, which has been long cultivated, is now very generally admitted; and therefore a more particular account, than has hitherto been given, of the means by which the most valuable new varieties have been obtained, may probably not be unacceptable to the possessor of the Pomona Herefordiensis, particularly if he be no botanist. Preparatory to 


\section{[ iii ]}

these experiments many varieties of the apple were collected, which had been proved to afford, in mixture with each other, the finest ciders; a tree of each was then obtained by grafting upon a paradise stock, and these trees were trained to a south wall, or if a Siberian crab, to a west wall, till they afforded blossoms; and the soil in which they were planted was made of the most rich and favourable kind. Each blossom of this species of fruit contains about twenty chives, or males, and generally five pointals, or females, which spring from the centre of the cup, or cavity of the blossom. The males stand in a circle just within the bases of the petals, or flower leaves, and are formed of slender threads, each of which terminates in a small yellow ball, or anther. It is necessary, in these experiments, that both the fruit and seed should attain as large a size, and as much perfection, as possible; and therefore a few blossoms only were suffered to remain upon each tree from which it was intended to obtain seeds. As soon as the blossoms were nearly full-grown, every male in each was carefully extracted, proper care being taken not to injure the pointals or females; and the blossoms, thus prepared, were closed again, and suffered to remain till they opened spontaneously. The blossoms of the tree which it was proposed to make the male parent of the future variety, were acceleraled by being brought into contact with the wall, or retarded by being detached from it, so that those were made to unfold at the required period; and a portion of their pollen or farina, when ready to fall from the mature anthers, was, during three or four successive mornings, deposited upon the pointals of the blossoms, which consequently afforded seeds. It is necessary in this experiment that one variety of apple only should bear unmutilated blossoms; for where other varieties are in flower at the same time, the pollen of these will often be conveyed by the bees to the prepared blossoms; and the result of the experiment will in consequence be uncertain, and unsatisfactory. 


$$
\text { [iv }]
$$

Every seed, though many be taken from a single apple, will afford a new and distinct variety, which will generally be found to bear some resemblance to each of its parents. Examples of this are presented in the Grange apple and Downton pippin, and in the Foxley apple and Siberian Harvey.

After varieties are thus formed, the operator has still to wait long before he can estimate the success of his labours. A seedling pear-tree does not often bear fruit till it is ten, and sometimes not till it is sixteen or eighteen years old; but a seedling apple-tree will generally produce fruit at six or seven years old, and sometimes even at four, when either of its parents has been the Siberian crab. 'The success of the experiment is also still uncertain: many of the new varieties will be worthless; and where the fruits are good the trees will often prove unproductive, or defective in health and vigour; and the planter must think himself fortunate if, under the best management, fifty seeds afford a single fine variety for the press; though many will probably be above mediocrity.

Many different methods of raising and preserving orchards are practised; but the following is that which I can best recommend. Let a soil of good quality be selected for a nursery, which should be trenched eighteen inches deep, and planted with seedling crab or pear stocks of one year old, each plant being placed at the distance of six feet from others. These will be fit for grafting at two years old; and an acre of ground, thus planted, will contain about 1500 trees, and consequently enough to plant about forty acres, where each tree stands at twelve yards distance from others. A nursery thus planted, when the trees are seven or eight years old from the seed, will form a more productive orchard than can be obtained by any other means with which I am acquainted; and during the earlier periods of the growth of the trees, they will be rather benetited than injured if the ground be planted with potatoes, or other low-growing crops, with proper manure. During 


\section{$[\mathrm{v}]$}

the growth of the trees in the nursery they should not be pruned to single stems, without leaves, as is usually done in nurseries; but each should retain many small lateral branches, which will tend to make the young trees grow strong and taper in their stems, and will also afford much fruit whilst the trees be very young. I would recommend the Downton pippin for an experiment of this kind, in preference to any other variety.

At the end of eight or nine years, from the time when the trees are first planted, they will have covered with their branches the whole surface of the ground, and will then begin to injure each other, if the whole be suffered to remain. At this period, therefore, every other row of trees, and at no distant subsequent period, every other tree in the remaining rows must be taken away, and if this be done with proper care, and leaving the roots at least two feet long upon each side of the trunks, such trees may be removed with still less risk than such as are much smaller. But to insure success, it will be necessary to take off much the greater part of the lateral branches; and the holes in which the trees are to be planted must be made not less than six feet wide and eighteen inches deep, placing the turf, if the field be pasture, in the bottom, and taking care that the trees be not planted deeper in the soil, than they previously grew. Each tree will require, during the first year, a stake and a few bushes to protect it; after which nothing more will be wanting than to wash its trunk annually with lime and water and cow diung, to defend it from the teeth of sheep and cattle.

The supernumerary trees should be taken from the nursery as soon afterwards as convenient; but with proper attention to the preceding directions, both pear and apple-trees may be removed with the most perfect success when twenty years old, and when their trunks are five or six inches in diameter.

Comparatively few of the Sulsscribers to the Pomona Herefordiensis will be interested in learning the art of making cider; and 


\section{[ vi ]}

were it otherwise, the minute description of the machinery and processes necessary would much exceed the intended limits of the present publication. I shall therefore only give a general outline of the most approved practice; and I must refer the reader, who wishes for further information, to a small work upon that subject, in which I have detailed every particular which will be found necessary to the inexperienced planter.*

The art of making fine cider and perry is exceedingly simple, when proper varietics of fruit, in a perfect state of maturity, can be obtained. Such fruit should remain in heaps of not more than twelve inches deep, in the open air till it has become perfectly mellow, and it should then be ground in a mill of stone till the pulp and rind are perfectly reduced, and have acquired a deep and uniform brown colour. The juice is then expressed, and placed in casks to ferment, where it is as soon as possible separated from its grosser lees; and excess of fermentation is prevented by placing the casks in a cool and airy situation, and by drawing off the liquor from one cask to another.

An opinion is very generally entertained that fine ciders and perries can be obtained from a few particular soils only; but this opinion has been derived from ill-eonducted experiments made with improper varieties of fruit; and I believe there are very few soils in which apples will grow, in which one amongst the five new varieties of the apple, which are represented in the annexed plates, will not afford cider of great excellence. The short period within which these varieties have come first into existence has not permitted sufficient experiments to be made, by which it can be accurately ascertained to what kind of soil each is best adapted; but I shall nevertheless endeavour to direct the planter, as far as I am enabled by such observations as $I$ have had opportunities of making.

\footnotetext{
* Treatise on the Culture of the Apple and Pear, third Edition.
} 


\section{[ vii ]}

The Grange apple, and Stead's kernel, do not appear to be greatly affected by the kind of soil in which they grow. In a deep and strong, and rather humid, loam, both acquire a larger size, and contain a larger portion of juice, and will therefore, in such soils, produce ciders of less strength and richness; but the general characters of both these varieties do not appear to be, in other respects, nuch altered. The Grange apple appears perfectly ripe in October, when it falls from the tree, and I thence supposed it to be incapable of being preserved even a few weeks; but I have subsequently seen it perfectly sound in March. In the beginning of December it is in perfection for the press, and it will probably afford as fine a cider as has at any time been produced.

The Downton pippin varies much in quality, according to the soil in which the tree grows. In a deep and somewhat humid loam the trees grow very rapidly, and are most exuberantly productive; but the fruit ripens ill and irregularly, and soon decays; and its juice is defective in richness. In a strong and argillaceous, but dry, loam, it acquires its greatest state of perfection for the dessert, continuing in season from November to April; but for the press, I believe it will be found to acquire, like the golden pippin, its greatest state of perfection in a more light and somewhat sandy soil.

The small size of the Foxley apple, renders it of little value except for the press, unless on account of its great beauty, and the extraordinary brilliance of its colours. As a cider apple, I believe it will be found to possess very great excellence; and it acquires nearly the same state of perfection in very different soils. The trees grow very rapidly, and are very productive of fruit

A single tree only of the Siberian Harvey has yet afforded fruit; and $I$ am thence wholly unable to decide for what kind of soil it is best calculated: but I believe it will succeed well in any except a deep and humid loam. In such a soil, however, the trees would grow 


\section{[ viii ]}

very freely, and would be abundantly productive; but I suspect that the fruit, in some seasons, would decay without falling from the trees; for it does not ever detach itself from the branch till long after it has become perfectly ripe, nor till it has become transparent, iike its female parent, the yellow Siberian crab. The richness of the juice of this apple, so far exceeds that of any other, that I am at a loss to conjecture the degree of strength which the cider will possess : but I suspect that if fermentation be allowed to proceed till all the saccharine matter of the juice is decomposed, under favourable circumstances, the cider will nearly rival in strength any genuine wine, which is now grown in France.

-To what further extent the saccharine matter may be increased in this, or in any other species of fruit, future experiment can alone decide. Nature appears to have made every species of esculent plant and fruit capable of endless change, and probably, relatively to the use of man, capable of endless improvement; and thus presents to him an ample and unbounded field, in which accident has hitherto usurped the place of art and science.

Respecting the execution of the coloured Plates, the Society have reason to hope that the Subscribers to the work will be perfectly satisfied; for the Plates first given, as samples, are inferior to those which succeed : they have nevertheless had much to regret in the loss, through ill health, of the skill and talents of Miss Mathews of Belmont, to whom they were indebted for all, except three, of the very excellent drawings, from which the Plates were taken. The remaining three, the Stead's Kernel, the Old Pearmain, and the Friar, were the work of a very young and inferior artist of my own family; but those were finished under my own eye, and were most perfectly correct; and whatever may have been defective in the drawings has not been transferred by $\mathrm{Mr}$. Hooker to the Plates. 



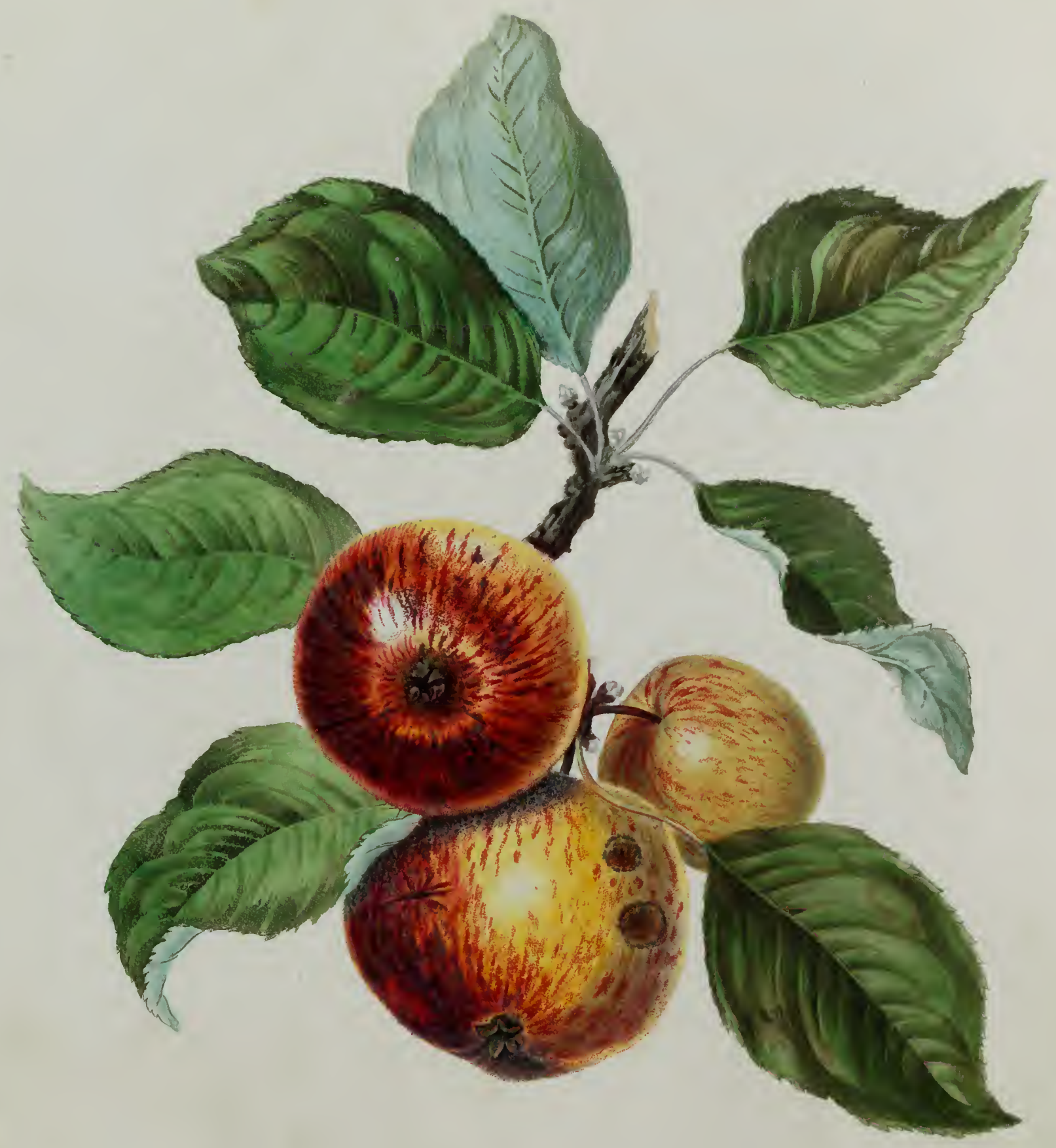

Bege. Hathens dett

Whe Siedstreatic,

th twotien fout 


\title{
POMONA HEREFORDIENSIS.
}

\author{
I. \\ THE REDSTREAK. \\ "With gold wose pulpous fruit \\ "With gold irradiate and vermilion shines." PHLIPS.
}

The Redstreak, or Redstrake as our ancestors wrote it, appears to have been the first fine cider apple that was cultivated in Herefordshire, or probably in England ; and it may even be questioned whether excellent cider was ever made, in any country, previous to the existence of this apple. The Redstreak is unquestionably a native of Herefordshire, and the credit of having raised it from seed, in the beginning of the 17th century, has been generally given to Lord SCUDAMORE, from whom it was, when first cultivated, called "Scudamore's Crab :" and if that nobleman did not raise it from seed, it appears extremely probable that he found the original tree growing upon his estate; and he certainly first pointed out the excellence of the fruit to the Herefordshire Planters.*

Trees of the Redstreak can now no longer be propagated; and the fruit, like the trees, is affected by the debilitated old age of the variety, and has in a very considerable degree

* Evelyn's Pomona. 
survived those qualities to which was owing its former fame ; the cider that has been made with it alone, within the last thirty years, having rarely proved good: but in mixture with other varieties it communicates its fine flavour; and in some instances a cask of genuine Redstreak Cider has been found to deserve all the commendations, which our ancestors gave it. I found the specific gravity of the juice of the Redstreak, when recently expressed from a selected sample of the fruit, to be 1079 , after the pulp had been thoroughly reduced, and exposed during twenty minutes to the air.*

* During the grinding of apples for cider, I have discovered that much air (probably pure oxygen) is absorbed; and during this absorption much saccharine matter is apparently generated; for the juice of very harsh and acid apples becomes rich and sweet, and acquires many degrees of specific gravity. In estimating the specific gravity of the recently expressed juice of those varieties of the apple and pear, which will be delineated in the succeeding pages, the fruit of each variety was selected as nearly as possible at the same degree of maturity, being ripe, but not mellow, and the process of preparing it was, in all cases, the same. 



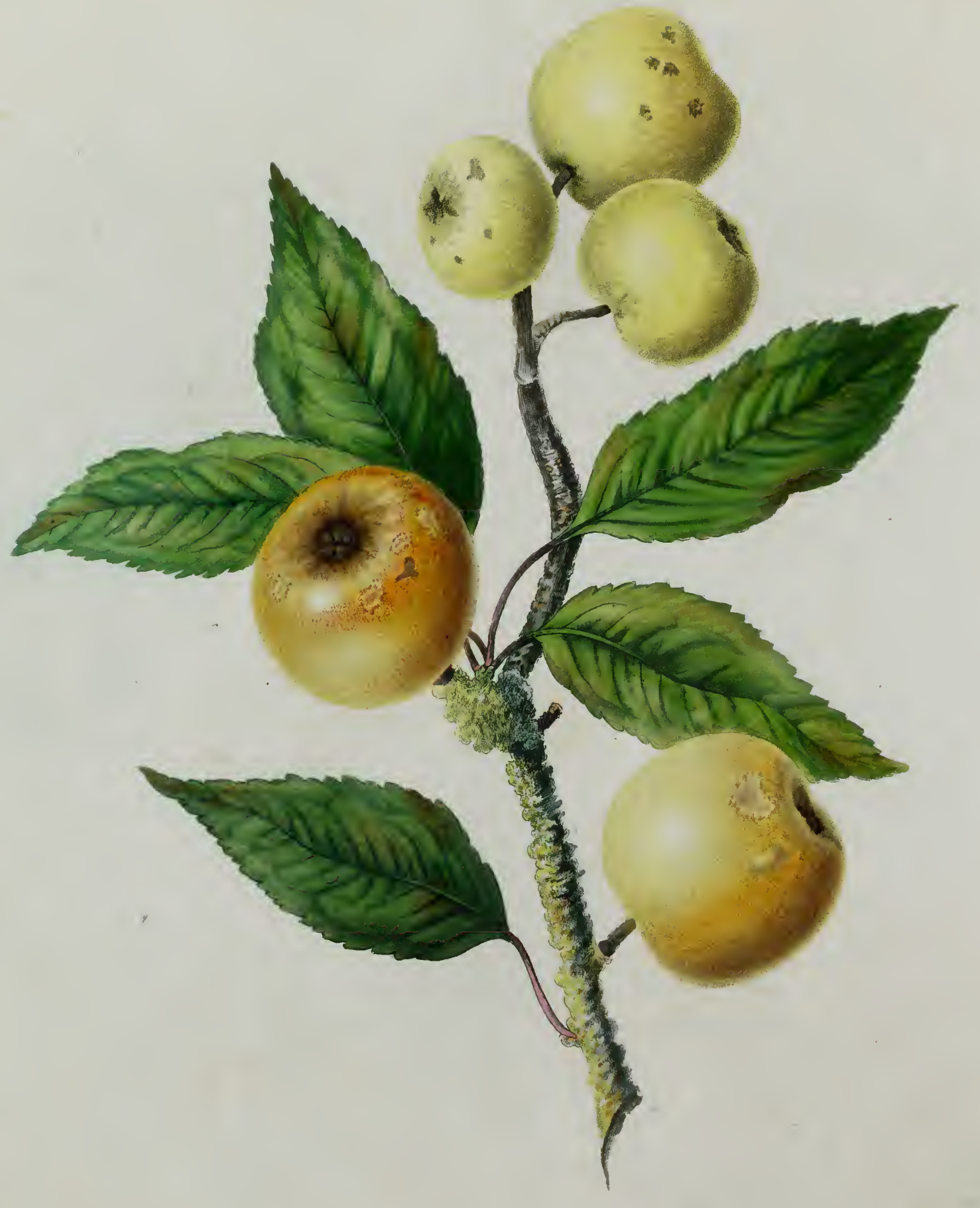

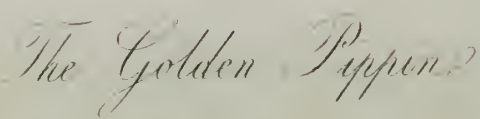


II.

\section{THE GOLDEN PIPPIN.}

The Golden Pippin is probably as old a variety of the apple, as the Redstreak, though the culture of it cannot be traced to quite so remote a period:* for the "Golding Pippin" of Parkinson, (who wrote in 1629) which he states to be the " largest and best of all sorts of Pippins," I conceive to have been a different variety; particularly as many of the apples which PARKINSON has named and described are certainly different varieties from those subsequently known by the same names.

The Golden Pippin is generally supposed to be a native of Britain, and to have been hence exported to the Continent: and I have seen it described and figured in a Dutch catalogue of fruits under the name of the "Engelsche Peppeng," and the "Engelsche Goud Peppeng ;" and the French name is merely a translation of the English name, being "Pepin d'Or."

The Golden Pippin appears to have been cultivated for the press in other parts of England, earlier than in Herefordshire, in which county it was, however, very extensively planted before the end of the 17 th century, and many very large orchards of it remained in the middle of the 18th century : and as long as the trees possessed even a moderate degree 
of health and vigour, the Golden Pippin retained the character of a very prime cider apple. But owing to the debilitated state of the variety, in which the vital principle appears to be nearly expended, much of the fruit generally remains imperfect and immature, as represented in the plate; and almost all the cider which it has afforded within the last twenty years has been crude and thin, or very frequently acetous. No attempts to propagate it, as a cider apple, are now made in Herefordshire ; though many trees of it, of very large size, still remain; and thinking it scarcely in existence as a cider apple, I neglected to ascertain the specific gravity of its expressed juice, which of course must admit of much varia-. tion in different apples, though taken from the same tree. 

III.

\section{THE FOXWHELP.}

This splendid apple is merely mentioned in Ever Y N's Pomona as a variety which "some commend;" and it probably did not, at that period, deserve greater commendations than were given to it. For the variety being then new, and the trees young, the fruit might attain a larger size, as well as abound with juice; and in this state the Foxwhelp affords a cider, which, though strong and well flavoured, is harsh and rough. But as the trees and the variety have grown older, much of the fruit has (in some soils and seasons particularly) become small and shrivelled, and under these circumstances the expressed juice is extremely rich and saccharine; and enters, in a greater or less proportion, into the composition of many of the finest ciders now made in Herefordshire, to which it communicates both strength and Havour.

Many of the old trees of this variety still appear healthy and vigorous; though grafts taken from them do not grow well: some attempts are nevertheless still made to propagate it; but I venture to predict that they will not be successful: for the grafts necessarily partake of a life that is nearly two centuries old, and the young stock can give nutriment only, not new life. The specific gravity of the juice of the large and juicy Foxwhelp I found to be 1076 , and that of the same variety, when small and shrivelled, to be 1080. This apple is, I believe, certainly a native of Herefordshire. 




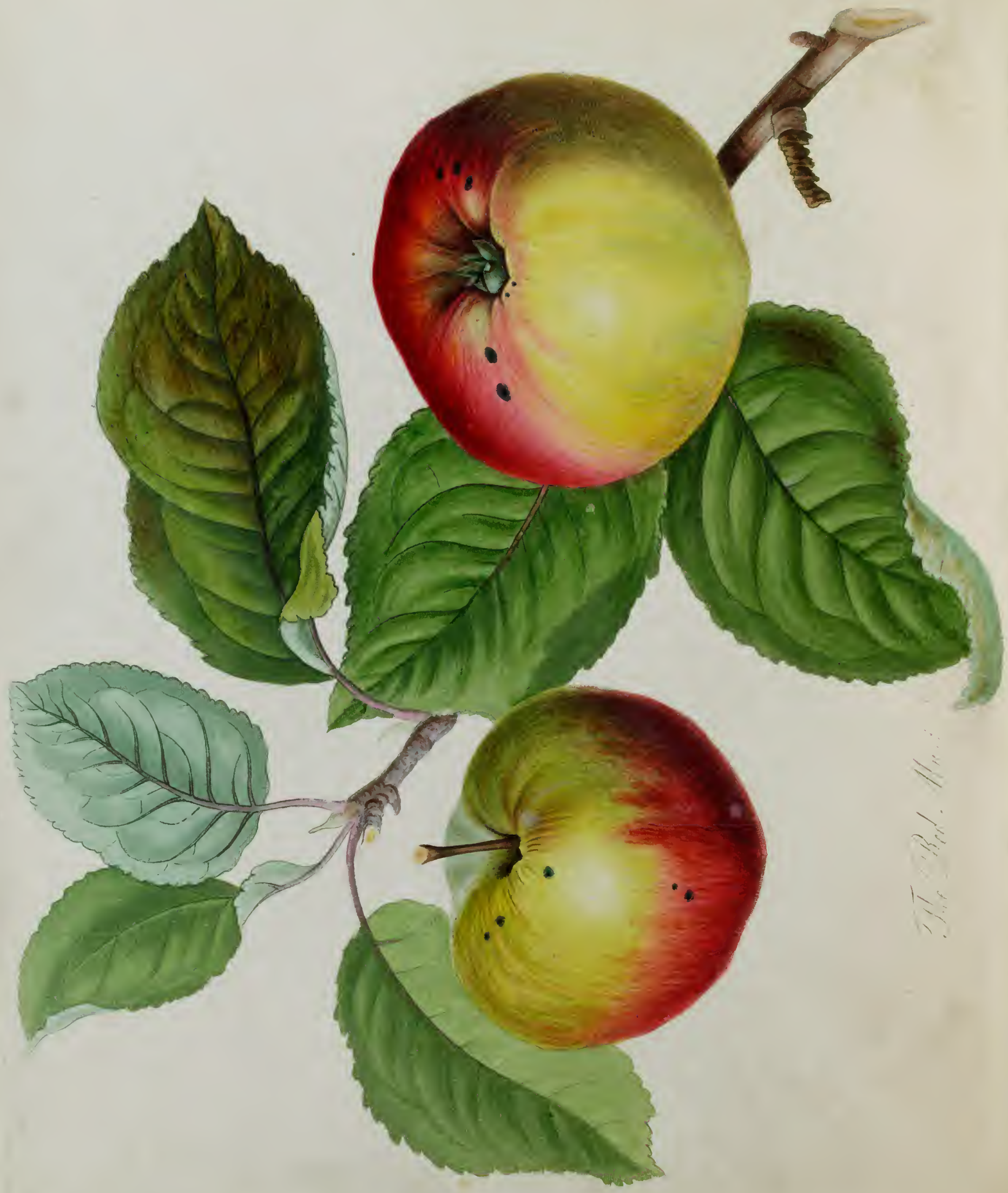


IV.

\section{THE RED MUST.}

The writers on orchards of the 17 th century have described three kinds of Musts, the red, the white, and the striped.* The red and white Musts were once very extensively cultivated, and are still found in the orchards of Herefordshire; but the striped has disappeared, and was probably a very old variety in the middle of that century ; for the author of the Herefordshire Orchard, who wrote in 1656, states that the planter of trees of this variety " commonly survives to see the decay of his own work."

The Red Must has, at all periods, been esteemed a good Cider $A$ pple, though the Ciders latterly made with it, unmixed with other Apples, have been light, and thin ; and I have never found the specific gravity of its expressed juice to exceed 1064. In mixture with other varieties it may however, have deserved the character which it has acquired; for it is universally admitted that a richer Cider is often made by mixing two or three varieties of Apples together, than either of those varieties, if used alone, would afford: and when after having ascertained the specific gravity of the juice of two varieties, the one being sweet and succulent, and the other dry and astringent, I have mingled the pulp of each in such proportions as to afford nearly an equal

* Evelyn's Pomona, and Worlidge. 
quantity of juice, the specific gravity of it has considerably exceeded the arithmetical mean. The tough and spungy pulp of one variety, by alternately absorbing and discharging the juice under the roller, may mechanically promote the absorption of air and the generation of saccharine matter; one variety may also afford an ingredient which others may want; and as the saccharine matter, under the preceding circumstances, is apparently generated whilst life still lingers in the fragments of the pulp, it is impossible to calculate the action of this busy agent; whose effects are every instant within our view, but with whose means of operating we must ever remain in total ignorance.

The Red Must is probably a native of Herefordshire, in the deep soils of which County the trees acquired a much greater magnitude than is common to the species. Philips has erroneously written " Musk :" 



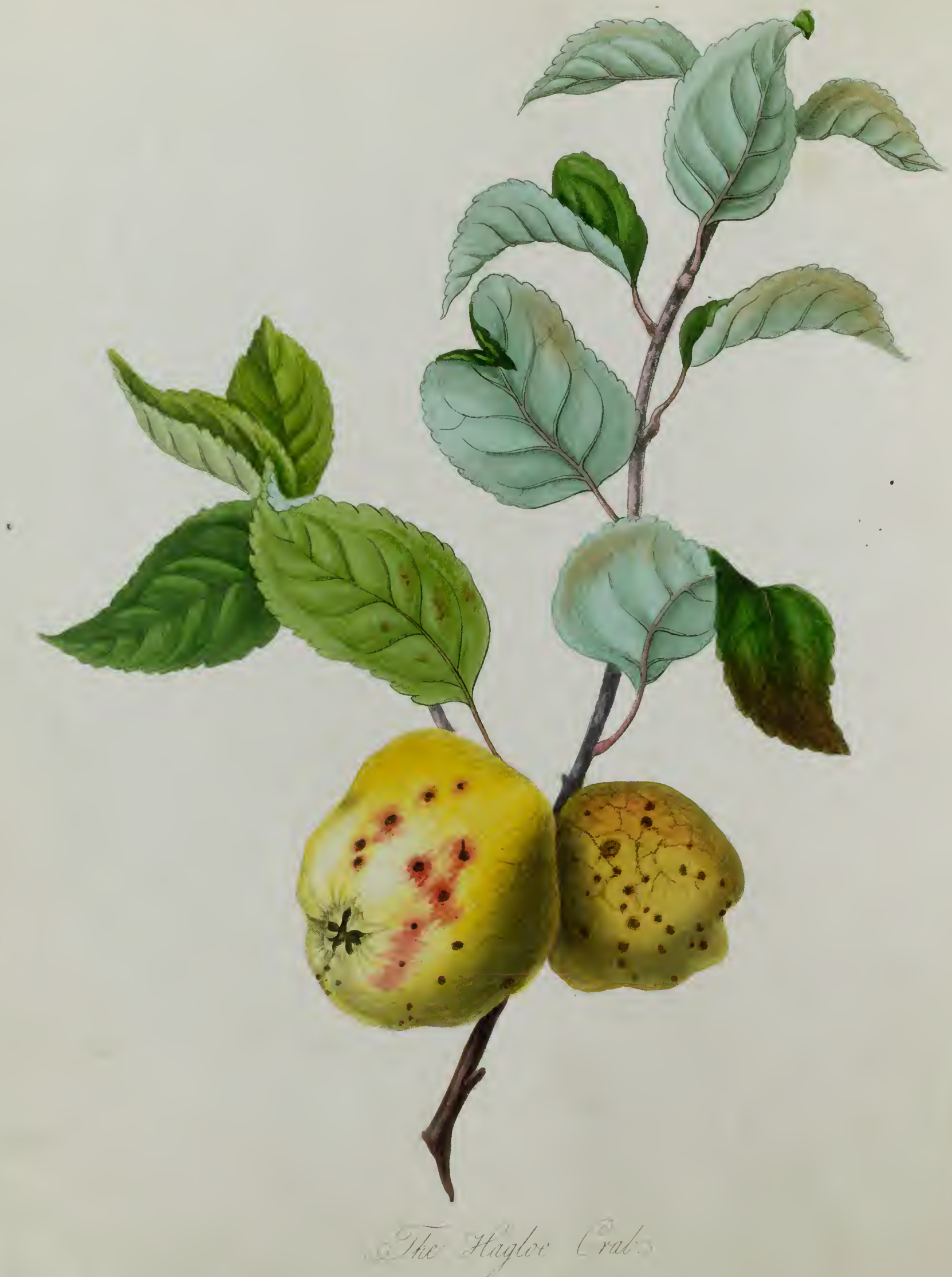


THE HAGLOE CRAB.

Mr. Ma Rsha L L, in his Rural Economy of Gloucestershire, is the first author who has mentioned this Apple; and he states it to have been raised from seed by the grandfather of Mr. BELLA M of Hagloe, * in Gloucestershire, about 70 years preceding the period in which he wrote, which was in 1789 . But I have reason to believe that this variety existed at an earlier period, and that Mr. BELLAMY's ancestor, on whose estate the original Tree probably grew, is rather entitled to the credit of having first discovered the excellence of the Apple, than to that of having raised it accidentally from seed; for some of my friends sought in vain many years ago for the original Tree at Hagloe.

Scarcely any Apple affords a finer Cider than the Hagloe Crab, when it grows in a dry soil on a basis of calcareous stone, in a warm situation and season : but under less favourable circumstances, the Cider it yields often retains too much of the crude harshness, which distinguishes the fruit, before it becomes perfectly mature. The Cider, however, generally possesses great strength and body, and the specific gravity of the juice, though expressed from an unfavourable sample of the fruit, in the present year, was 1081 . The Trees are rarely very productive of fruit, and there are not many soils and situations in which the Apple is capable of acquiring maturity and perfection.

* In the Parish of Awre. 




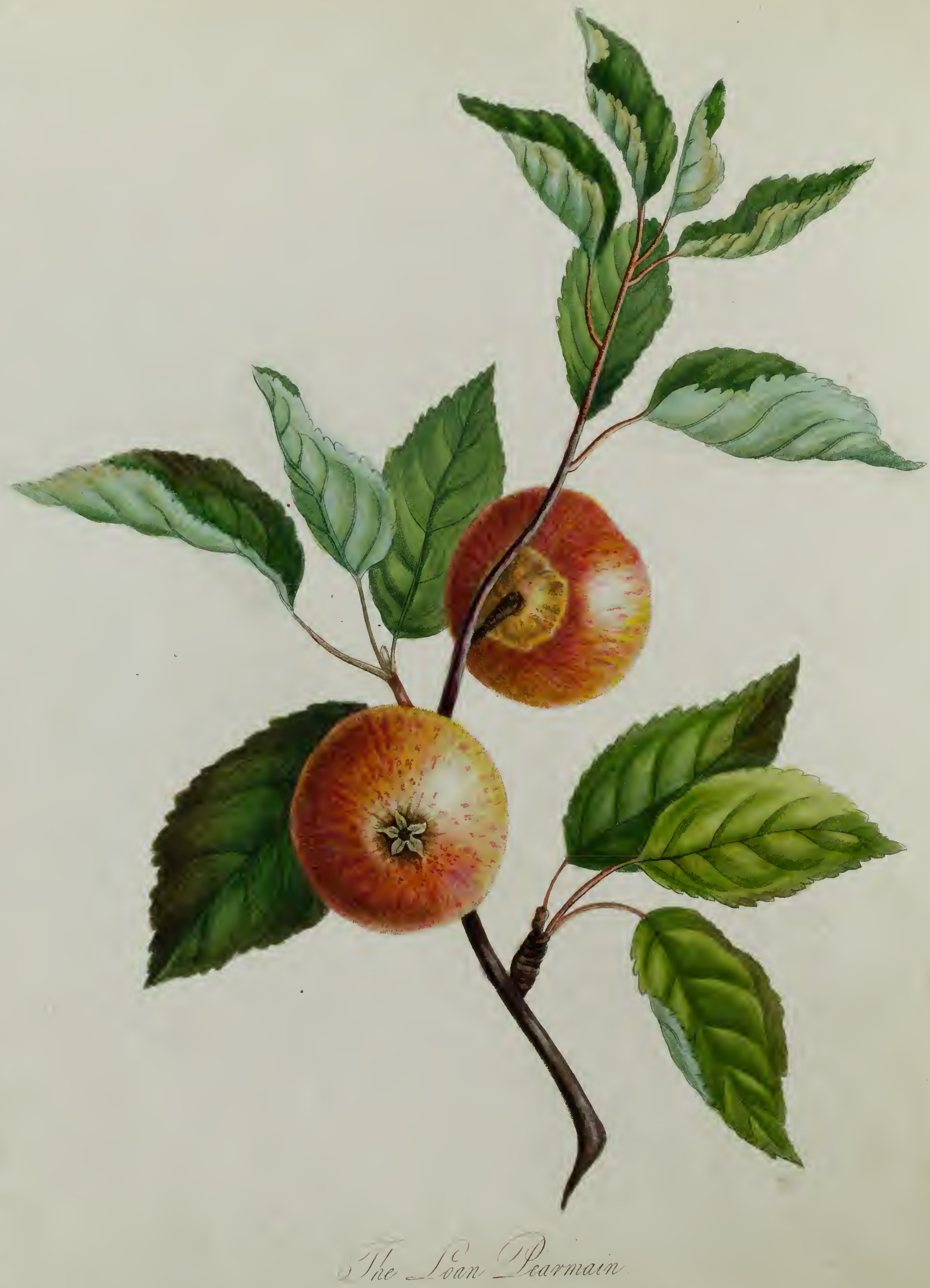


VI.

\section{THE LOAN PEARMAIN.}

The Loan Pearmain is not, I believe, found in any Catalogue of Apples of the 17th century; and if it existed even in the latter part of that period, it was probably as a single seedling tree; for the state of the variety does not now indicate any marks of old age, and orchards of it might still be raised; though they would probably be of short duration. As a Cider Apple the Loan Pearmain possesses much merit, and contains a considerable portion of saccharine matter combined with a good deal of astringency; but the trees are very subject to become much encumbered with a multiplicity of slender shoots, and are by no means good bearers. The specific gravity of the expressed juice is about 1072.

WORLIDGE, who wrote in 1678 has called the Marygold Apple " Joanes Pearmain," and the anonymous author of the "Complete Planter and Cyderist," printed in 1685, has called the same Apple "Lones Pearmain," whence the name of the Loan Pearmain, is, not improbably, derived. The Loans Pearmain, of the nurseries about London, is a different variety. 




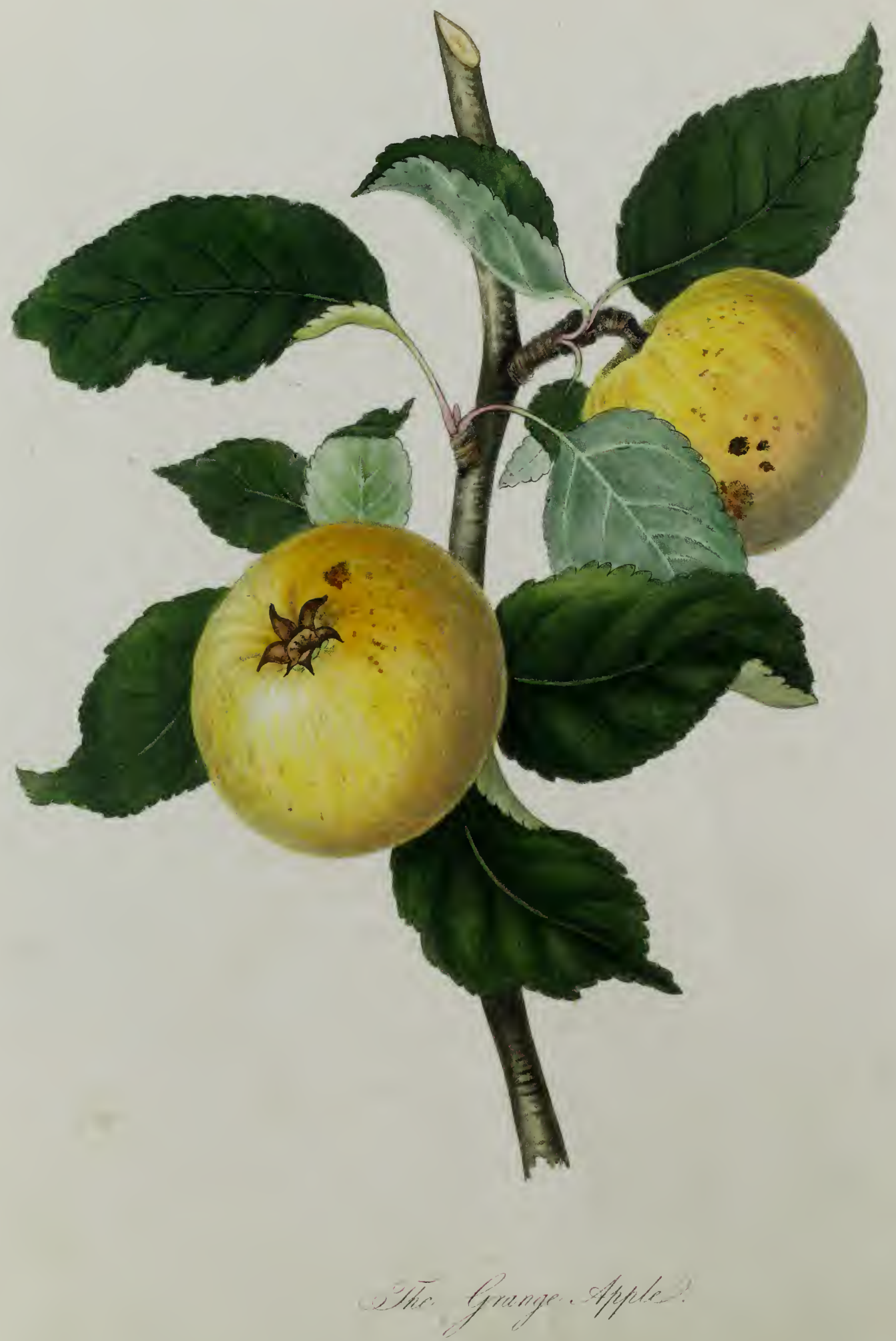


VII.

\section{THE GRANGE APPLE.}

The Grange Apple is of modern date, having sprung from seed in my nursery in the year 1792. It is the offspring of the Orange Pippin, of which a delineation is given in the succeeding plate, and the produce of a blossom which was deprived of its stamina, and subsequently fertilized by the pollen of the Golden Pippin. It is an established maxim, amongst breeders of improved animals, that the males and females, from which they propagate, must not be nearly related to each other; and however widely plants and animals differ from each other, very extensive experience has satisfied me that the same maxim is equally applicable to both.

The Grange Apple inherits much of the character of its male parent, both in external appearance and flavour, and will probably prove an excellent Apple for the Press, the specific gravity of its juice, expressed from a very perfect sample of the fruit, having been 1079.* The trees of this variety grow very freely in favourable soils, and the fruit, in moderately warm situations and seasons, ripens about the middle of October : it obtained the premium annually given by the Agricultural Society of Herefordshire for the best Cider Apple, recently obtained from seed, in the year 1802.

* The specific gravity of the juice of the Golden Pippin, in the same soil and season, was 1078. 



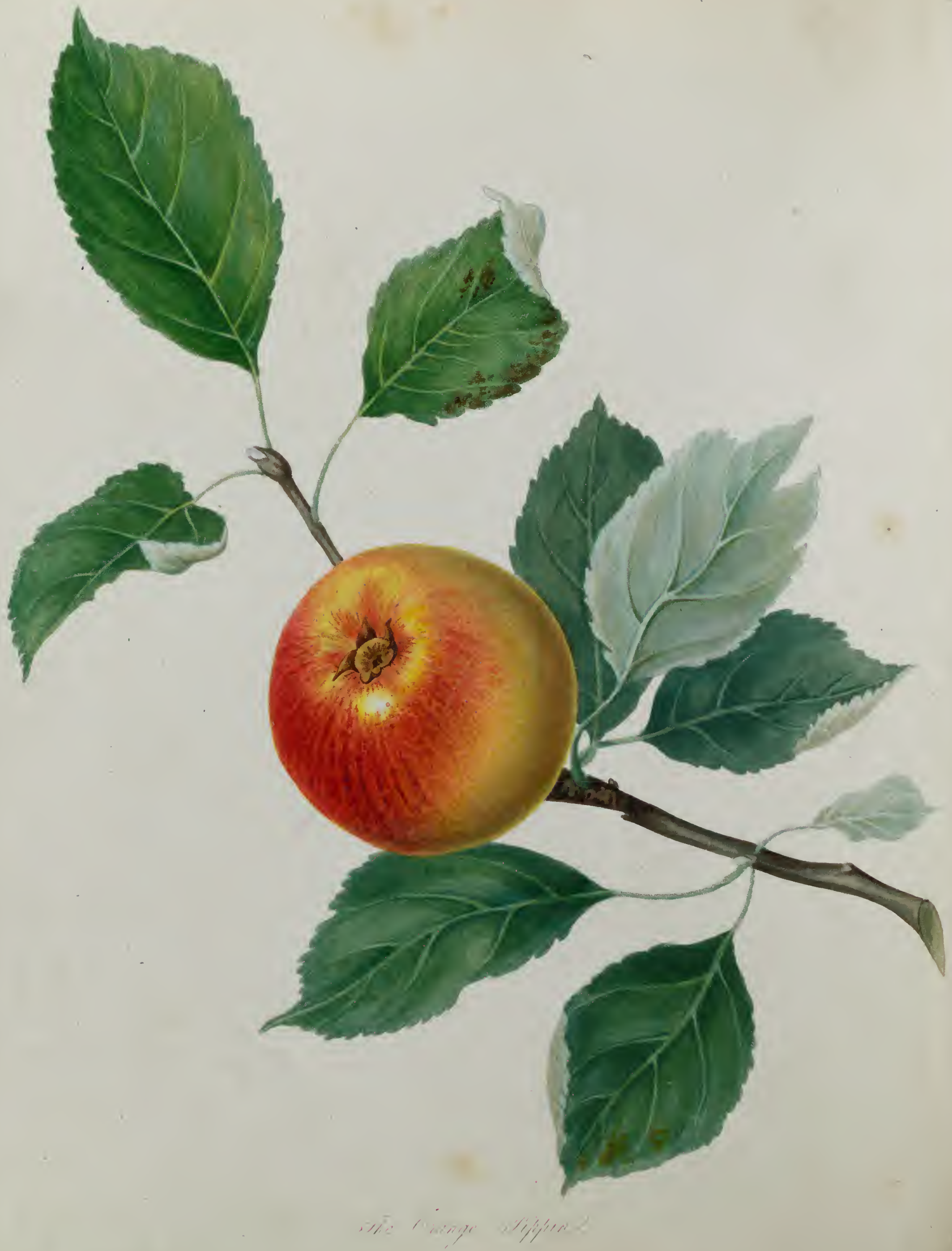


VIII.

THE ORANGE PIPPIN.

The Orange Pippin is cultivated in different parts of the County of Hereford under different names, and has been not unfrequently confounded with the Loan Pearmain, which it somewhat resembles in form and colour; but it is a larger and a much more sweet apple. The name does not seem perfectly appropriate, for the colour of the apple is very different from that of an orange : but when the crop of fruit is perfectly ripe, and seen at such a distance that the red and yellow colour are mingled and blended together, the effect on the eye may be conceived to be not very widely different from that which a similar crop of very ripe Seville Oranges would produce; and from this circumstance the Orange Pippin possibly derived its name. It is not apparently a very old variety; for young trees of it still grow freely and bear well : but I have seen trees of it, which were at least eighty years old : and therefore the variety can now scarcely deserve culture, though it is certainly an excellent cider apple, and its yellow pulp communicates a beautiful golden tinge to the juices of other varieties. The specific gravity of its juice is about 1074. I am ignorant of its native country, and of its history previously to the last thirty years. 




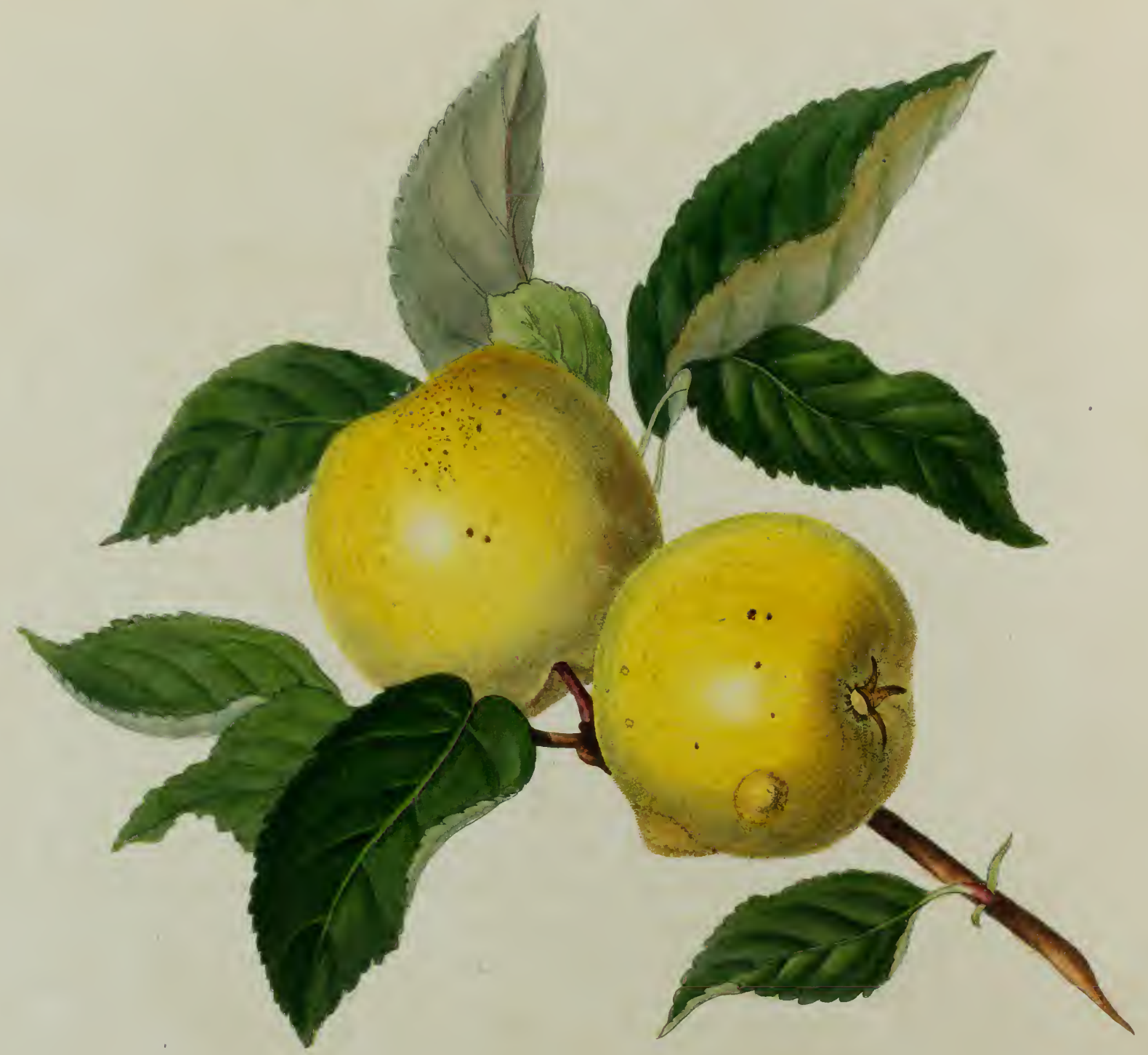

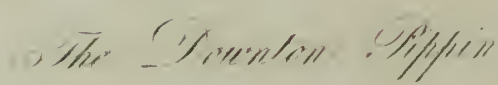


IX.

\section{THE DOWNTON PIPPIN.}

The Downton Pippin sprang, like the Grange Apple, and in the same year, from a seed of the preceding variety, and from the pollen of the Golden Pippin. It a good deal resembles its male parent in form and colour, and still more nearly in flavour, and it is, I believe, entitled to the first place amongst new varieties, as a fruit for the dessert. The trees grow very freely, and are most exuberantly productive of fruit, the grafts inserted in one season usually affording blossoms in the succeeding spring. Linnæus was of opinion that the character of the male parent generally predominated in the exterior of the offspring, and both the Grange Apple and Downton Pippin might be adduced as examples in support of his hypothesis; which nevertheless I have had, in many other cases, ample reasons to reject. The Downton Pippin ripens in the end of October; but it may be preserved till March. The specific gravity of its juice, when expressed from a well ripened sample of the fruit, is about 1080. The original tree, with that of the Grange Apple, is growing at Wormsley Grange, in Herefordshire.

There is a degree of freshness in the bark, both of this and of the Grange Apple, that is not generally seen in older varieties; and the leaves are more green than is common when the fruit is ripe. The drawings are, however, perfectly accurate, and are portraits of branches selected by myself from young trees in my nursery. 




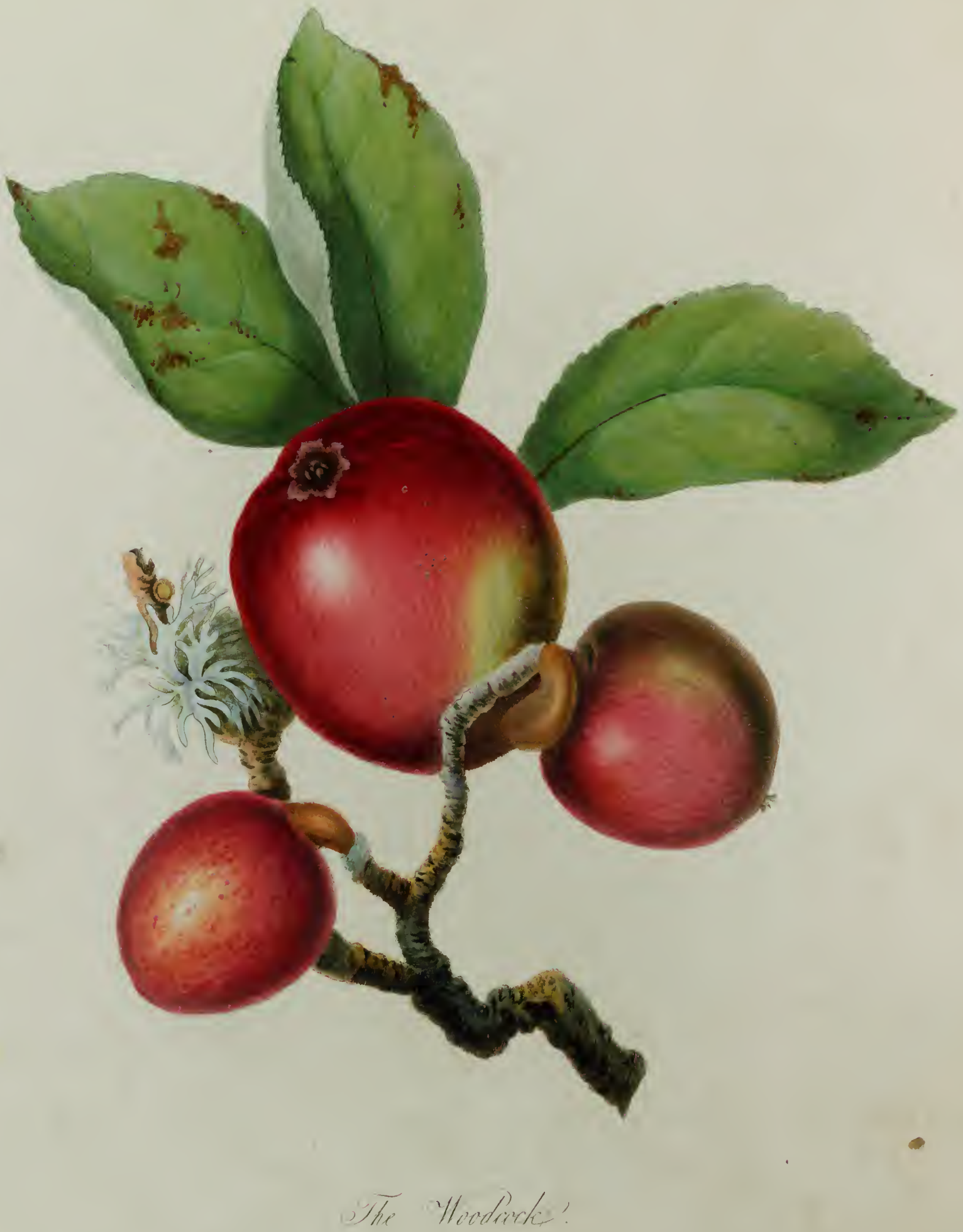


X.

\section{THE WOODCOCK.}

The Woodcock is frequently mentioned by the writers on orchards of the 17 th century as a cider apple of great excellence; and subsequent experience has justified the character, which they have given of it. But the variety has apparently survived the period allotted it by nature, and, like every other of equal age, it has long ceased to deserve the attention of the planter.

The Woodcock is generally supposed to have derived its name from an imaginary resemblance of the form of the fruit and fruit-stalk, in some instances, to the head and beak of a woodcock; but it may possibly have been so called from the name of the person who raised it from seed. The specific gravity of its juice is about 1073. . 




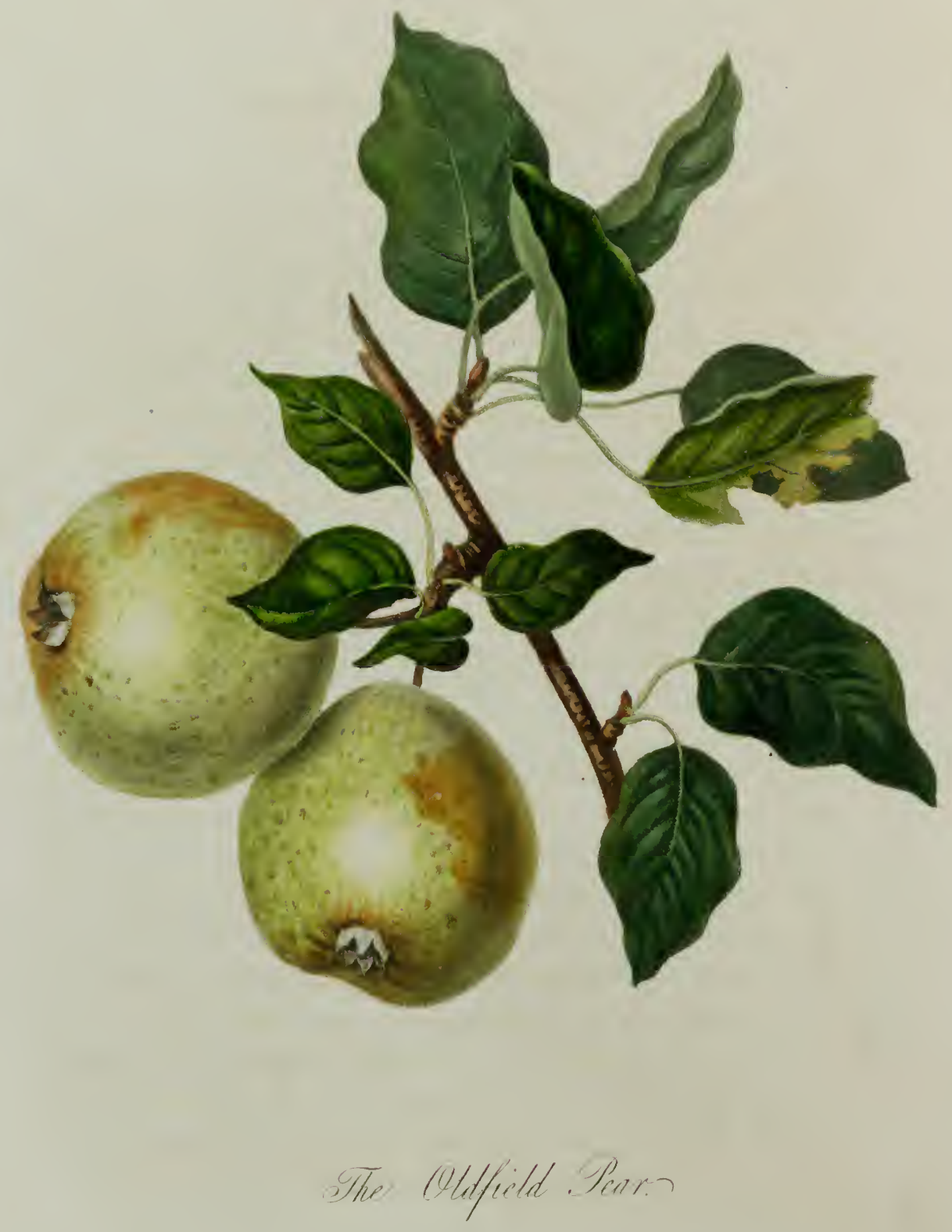


XI.

THE OLDFIELD PEAR.

This pear does not appear to have been known in the seventeenth century, nor even in the beginning of the eighteenth, for it does not occur in any of the older catalogues of fruits ; nor is it mentioned by Philips. It appears, however, to have been much cultivated soon after the time of the last mentioned writer, and has subsequently been more extensively planted than any other variety. The perry it affords is sweet and well flavoured; and it possesses, generally, a considerable degree of strength : but it is not often free from defect, which is common to almost ever kind of perry, that of leav. ing an unpleasant sensation of acidity on the palate.

The trees of this variety grow freely, and are very productive of fruit, and at an earlier age than those of almost any other variety.

The Oldfield Pear is generally believed to have derived its name from an enclosure called the Oldfield, near Ledbury, in Herefordshire, where an old tree still stands, which is supposed to be the original tree of this variety: but I was informed, in answer to enquiries which I made about twenty five years ago, that this tree has evidently been grafted, and that the original tree (which had once grown in the same field) had at that period long ceased to exist. The specific gravity of the juice of this, (as of all other pears) I have found to be subject to much variation, when obtained from fruit of equal maturity, but from different soils. The average weight was about $\mathbf{1 0 6 7}$. 
$\cdots$ 



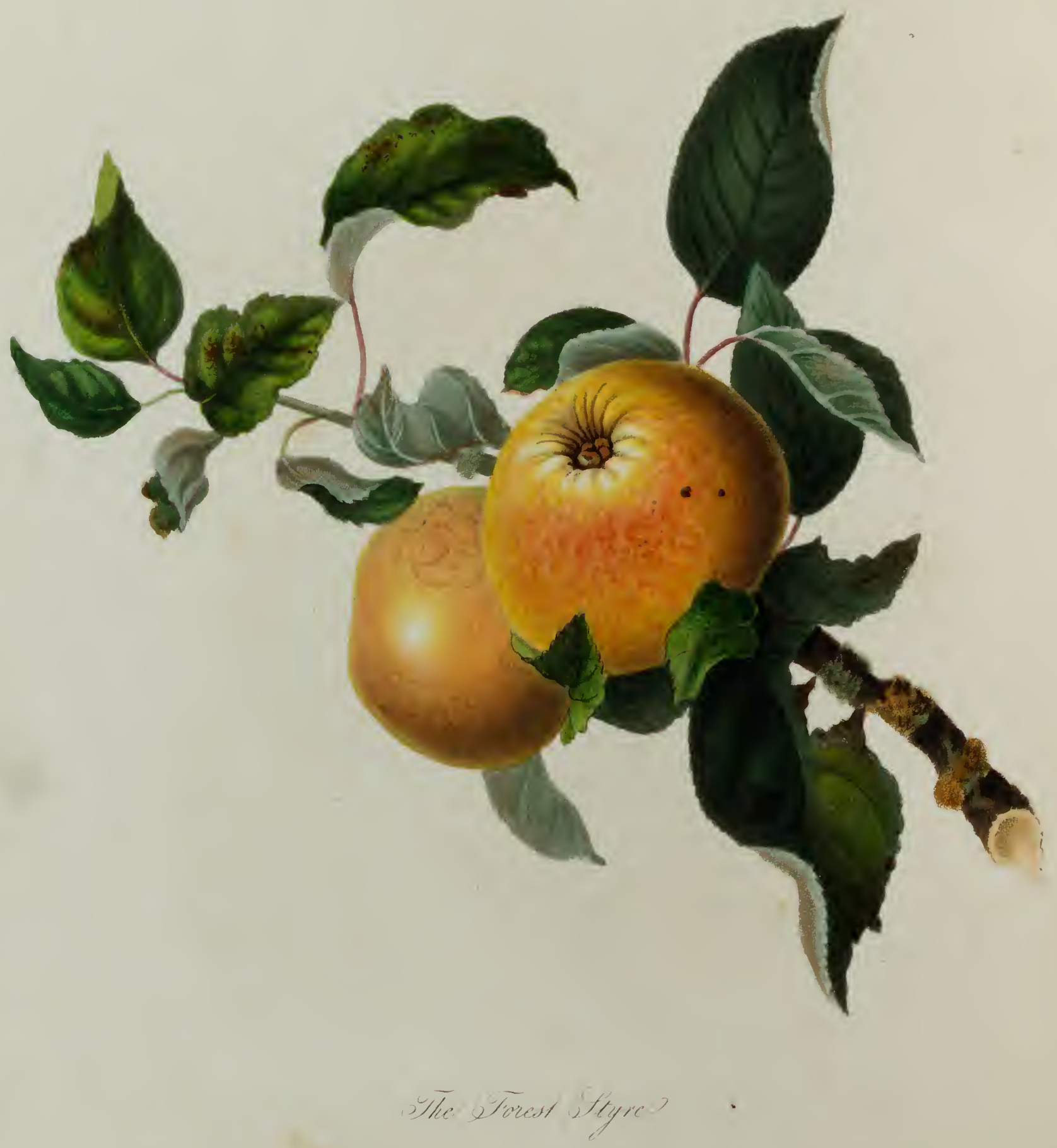


XII.

\section{THE FOREST STIRE.}

The Forest Stire is almost universally supposed to afford a stronger cider than any other kind of apple. I am, however, much inclined to doubt its pretensions in this respect, and to believe that the juice either of the Hagloe Crab, or Brandy Apple, if obtained from fruit of equal maturity, and fermented with equal skill, would be found to afford, by distillation, as much, if not a greater quantity of ardent spirit. The Stire is a native of Gloucestershire, and is planted principally in the light soils in the neighbourhood of the Forest of Dean, where it affords a stronger cider than in the deeper soils of IHerefordshire. I have not been able to find any account of it previously to the publication of Philips's Poem,* where it is called the Stirom, on what authority I do not know.

The trees of the Forest Stire, are not by any means very productive of fruit; and the fruit itself contains but a very small portion of juice; the specific gravity of which, I have observed to vary from 1076 to 1081 , though obtained from samples of equal maturity and apparent perfection; but which were produced by different soils. The Plate presents the apple in its most perfect and beautiful state.

This variety, as Mr. Marshal in his Rural Economy of Gloucestershire has remarked, is decaying rapidly. 




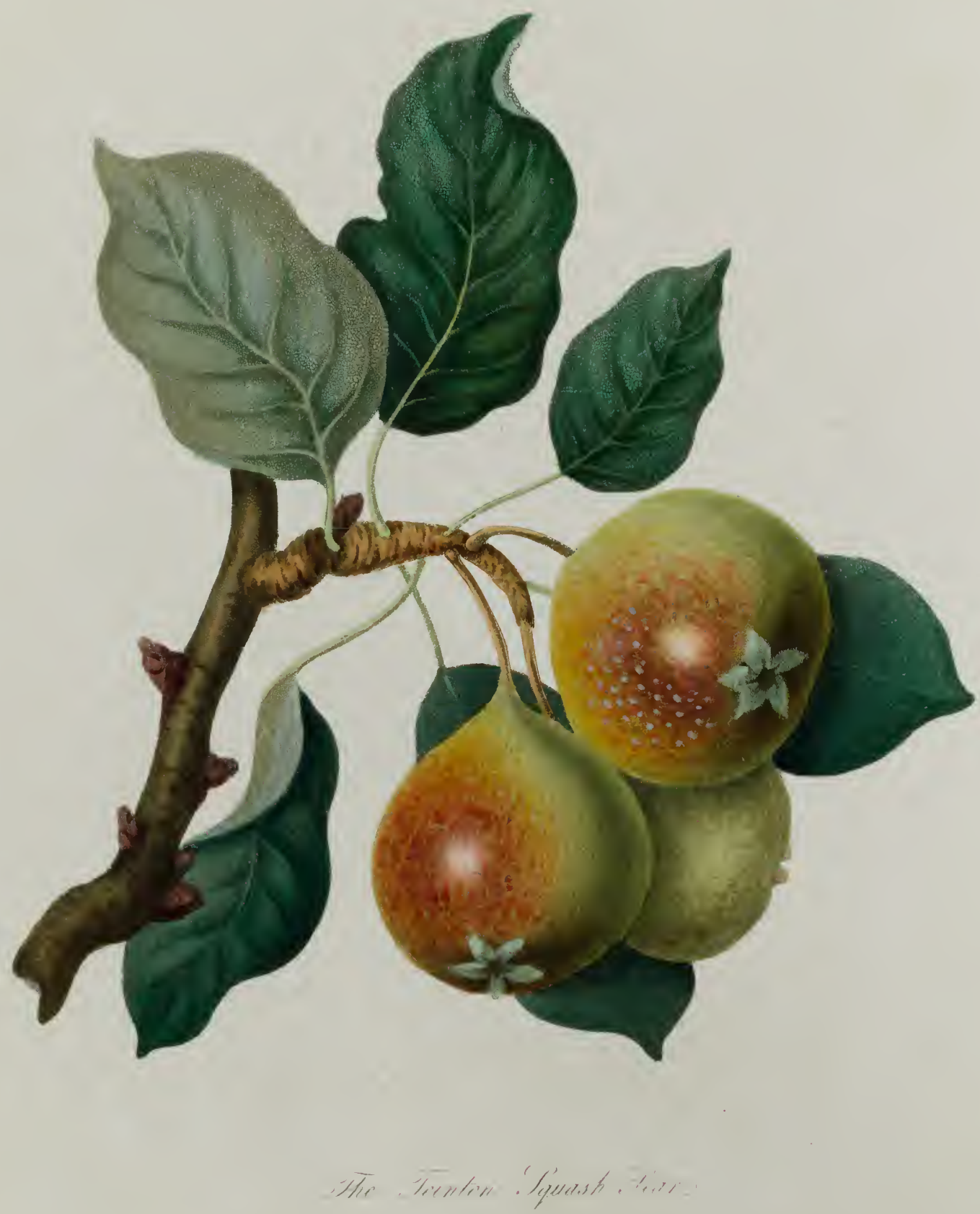




\section{XIII.}

\section{THE TEINTON SQUASH PEAR.}

I have not been able to discover the name of this pear in any old catalogue of fruits; though the immense bulk, and obvious antiquity of the trees, sufficiently prove, that it has been very long cultivated in Herefordshire, and the adjoining county of Gloucester; of which it is supposed to be a native. The Red Squash is, however, mentioned by Evelyn and Worlidge, and I suspect that the name of the Teinton Squash has been subsequently given to the same pear, from Teinton in Gloucestershire, where it has been much planted, and where it affords perry of the greatest excellence.

When the juice, which this pear produces, has been ripened in a favourable season, and has been subsequently well managed, it affords a much finer liquor than any other pear; but it is not very often found entirely free from the same keen acid, which deducts so much from the merits of the Oldfield perry, and which probably occasions both liquors to disagree with so many constitutions. The Teinton Squash perry has, I believe, been often sold for Champaigne, which it resembles a good deal in colour and briskness; but I have never been so fortunate as to discover any further resemblance between the two liquors. The trees of this variety are in the last stage of decay. I have not had an opportunity of ascertaining the specific gravity of the juice. 




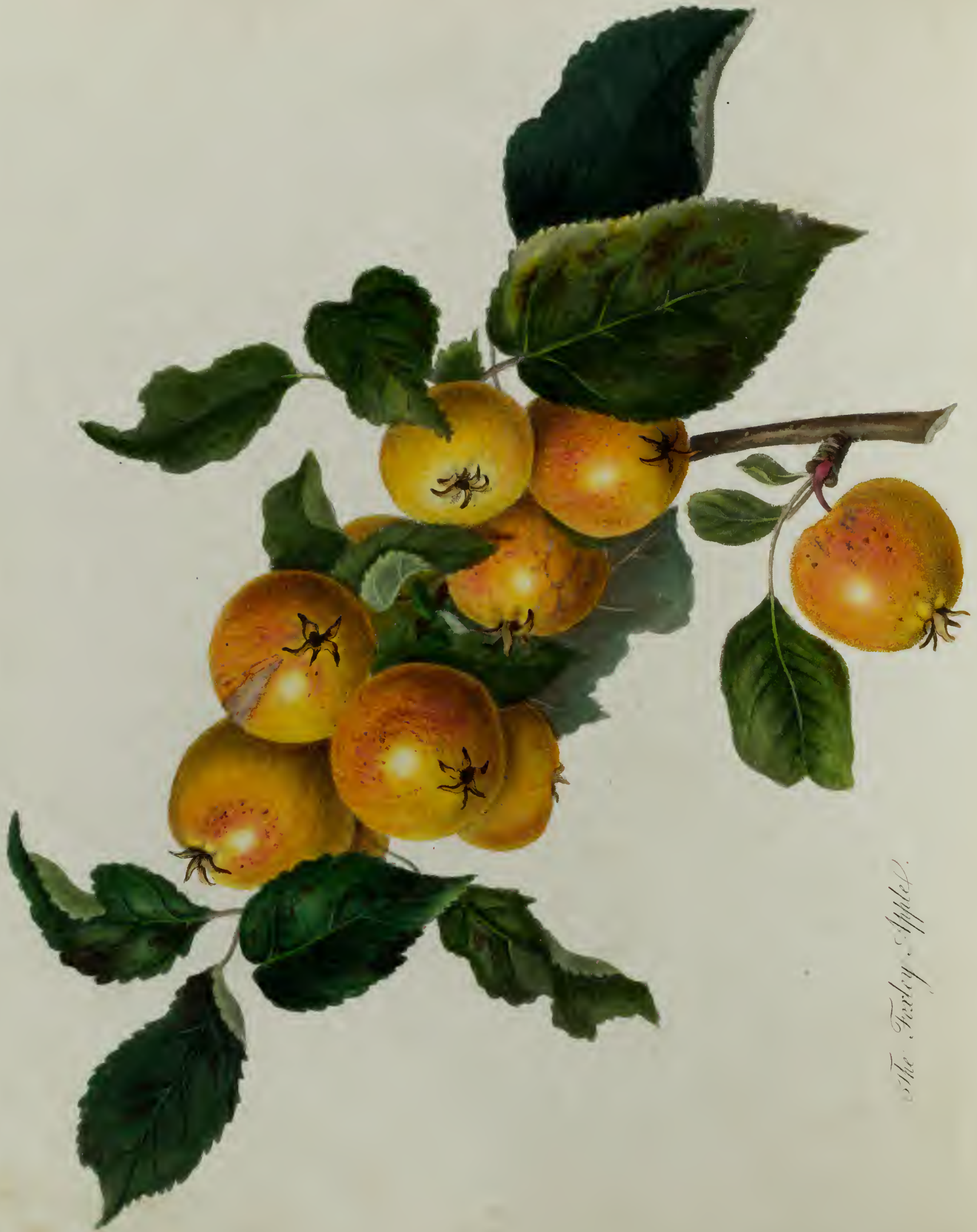


XIV.

THE FOXLEY APPLE.

This singular little apple sprang from a seed of the yellow Siberian Crab, and the Pollen of the Orange Pippin*; and it affords a remarkable combination of the apparently discordant qualities of its male and female parents. Its wood, its leaves, and blossoms, are those of a Crabtree, and are, to an extraordinary extent, patient of cold and unfavourable weather; whilst the fruit rivals the Golden Pippin in sweetness.

The native Crab of our woods was first transmuted into a rich apple by culture through successive generations; and during its progressive changes it became habituated to culture, and, like every other plant under similar circumstances, grew more and more dependent upon the care of man, as it became better adapted to his service. A rich apple, therefore, when thus generated, requires a continuation of that culture from which it first derived its existence, and is rarely, or never, well calculated for poor soils, or unfavourable situations. But when a variety, as in the present inslance, is the offspring of parents of totally dissimilar chaacters; when one parent has received all the improvements

* See Plate the 8th. 
that high culture can give, and the other possesses all its native hardiness and vigour; almost every possible combination and mixture of such characters (though the constitution of the female parent will generally be prevalent) will be presented in the offspring; and, without the aid of the grafter, a Golden Pippin will sometimes, though rarely, be seen to adorn the thorny branch of a Crabtree.

The Foxley Apple will, I believe, be very generally thought to deserye culture, as a tree of ornament, as well as any of its species, or congeners ; for the colours of the fruit are rather more intense and brilliant than the plate represents them; and I believe that no situation can be found, in which our native Crab will grow, and produce fruit, where the Foxley Apple will not afford a fine cider.

The original Tree grows in my Nursery at Wormsley Grange; but the fruit derived its name from Foxley, the seat of my friend Mr. Uvedale Price ; in whose garden, on a grafted Tree, it first acquired maturity. The specific gravity of its juice is about 1080 ; and it obtained the annual premium of the Herefordshire Agricultural Society in 1808. 


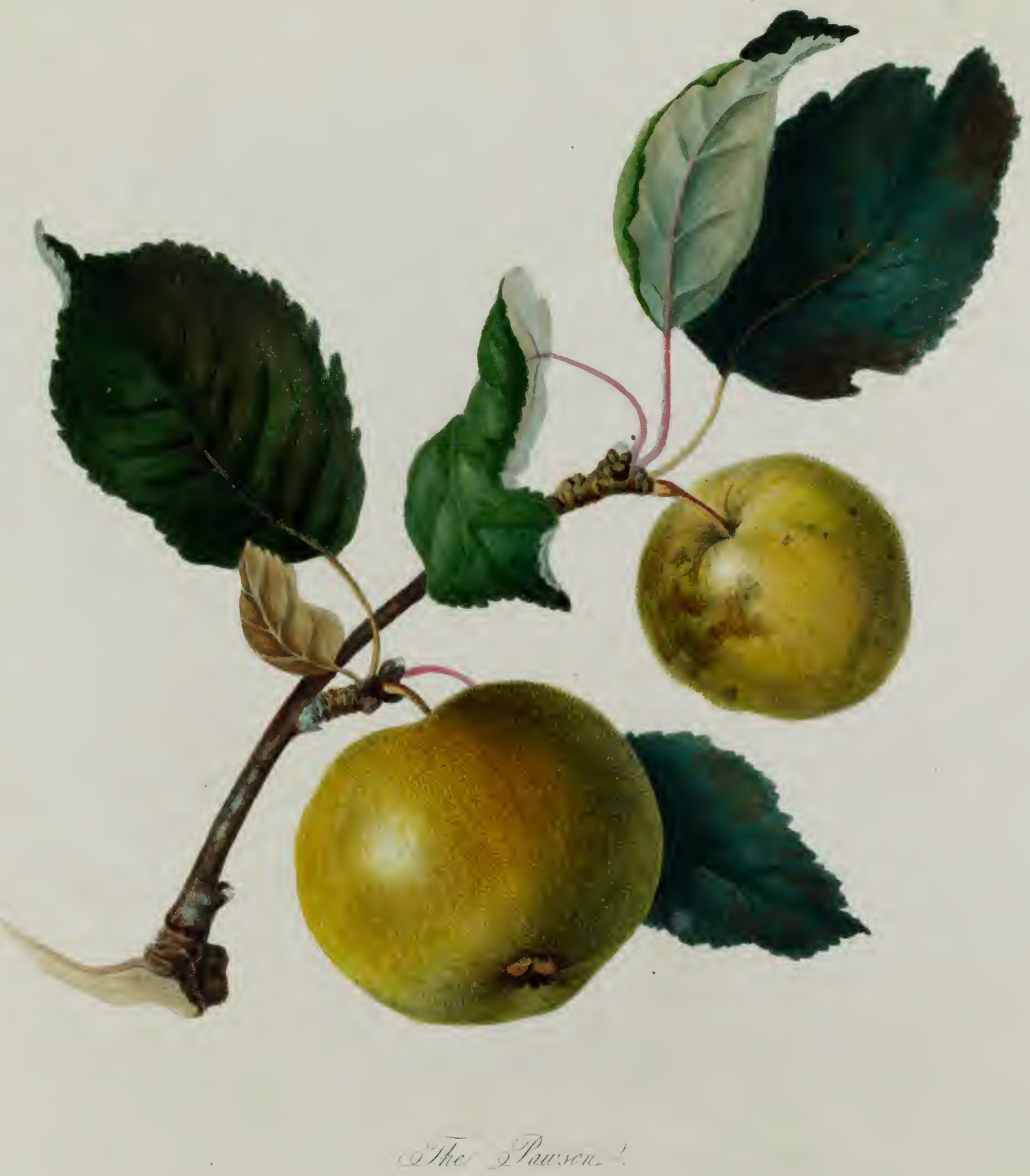


$\mathrm{XV}$.

\section{THE PAWSAN.}

Many trees of the Pawsan are found in the south-east, or Ryeland District of Herefordshire, which have apparently stood at least a century; and therefore it is probable that the writers on orchards of the 17 th century were not unacquainted with this fruit. It is not, however, mentioned by any of them, and therefore, if the fruit was known at that period, the planters, probably, were wholly ignorant of its merits.

The external character of the Pawsan is not by any means that of a fine Cider Apple; but its pulp is exceedingly rich and yellow ; and it sometimes affords, perhaps without any exception, the finest liquor, which is obtained from the juice of the apple. But the trees are generally unproductive; and the fruit does not ripen well except in favourable situations and seasons, and excess of fermentation in consequence too often frustrates the hopes of the Planter.

The form of the Pawsan is often less oblate and flat than the plate represents it; but, as in other varieties, this fruit generally possesses most richness and flavour, when its form is most compressed. I am. ignorant of the source from which the Pawsan derives its name: the specific gravity of its juice is about 1076 . 




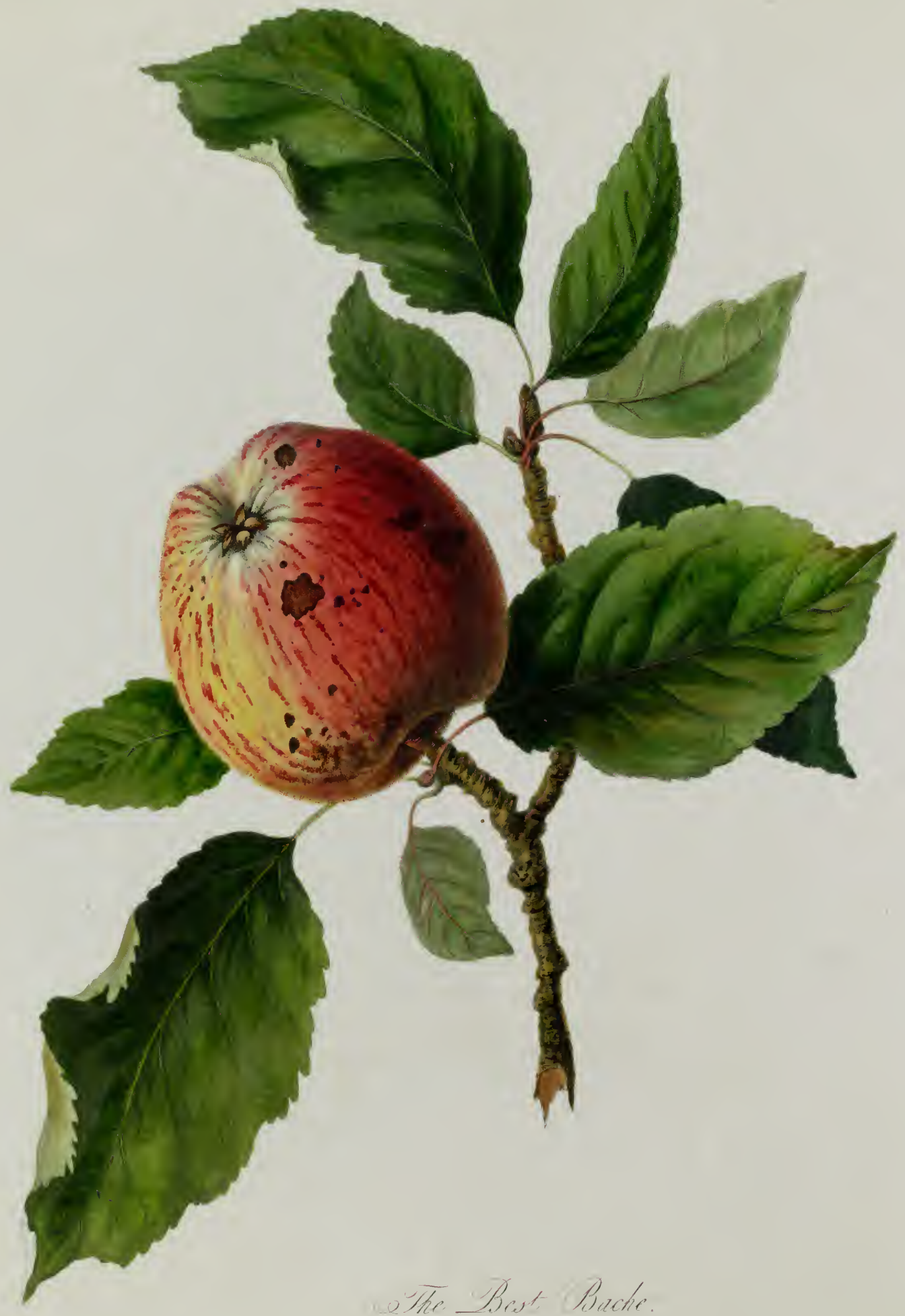


XVI.

\section{'I'HE BEST BACHE.}

T'his apple does not appear to have been known to the writers of the century before the last; for it does not occur in any old catalogue of the varieties of apples of that period; and it is not improbable that it is a variety of more recent date. The origin of the name is unknown: it may possibly have been obtained from the name of the field, or farm, where the original tree grew; but as it has sometimes been called Bache's Kernel, it more probably derives its name from that of the person who first raised it from seed, or was subsequently supposed to have improved it by culture: for the planters of the 17th century erroneously conceived that the character of every variety might be permanently changed, and improved, by appropriate management of the mature seed, and of the plant, subsequently to its evolution.

The Best Bache is principally cultivated in the South-east part of Herefordshire. The specific gravity of its juice is about 1073. 


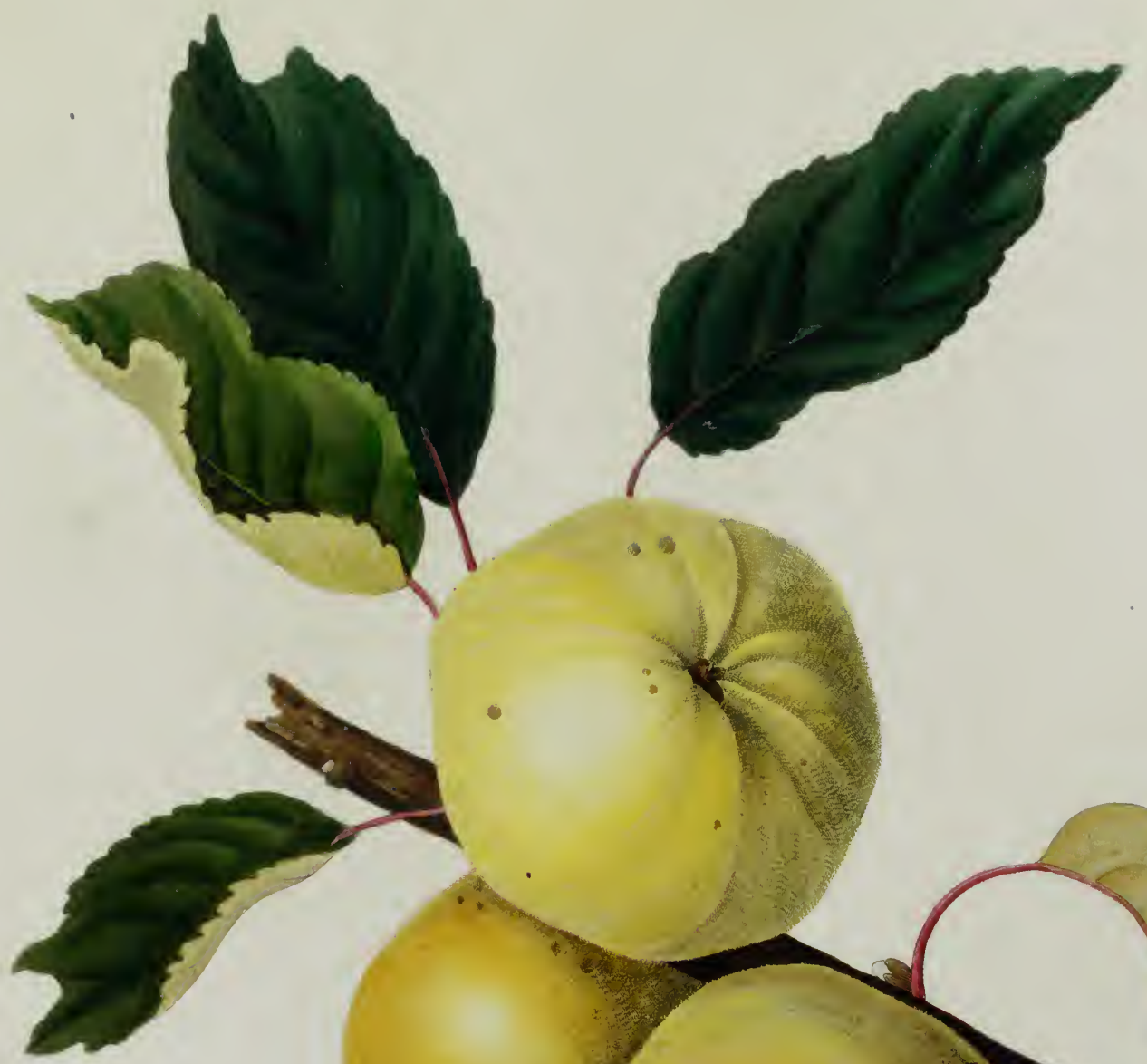


\section{XVII.}

\section{THE YELLOW ELLIO'T.}

The Yellow Elliot was well known, and highly estimated, by the planters of the 17 th century. It is a very astringent and harsh, though not very acid, apple; and it afforded a cider which grew soft and mellow with age; and, with other ciders of similar character, it once occupied its proper place at the Yeoman's 'Table; but from which it is now driven by very inferior liquors under the borrowed name of wine.**

The specific gravity of the juice of the Yellow Elliot is about 1076. It probably derived its name from that of the person who raised it from the seed.

* _ Thy cask shall slowly mitigate The Eliot's roughness. Philips's Cyder. 



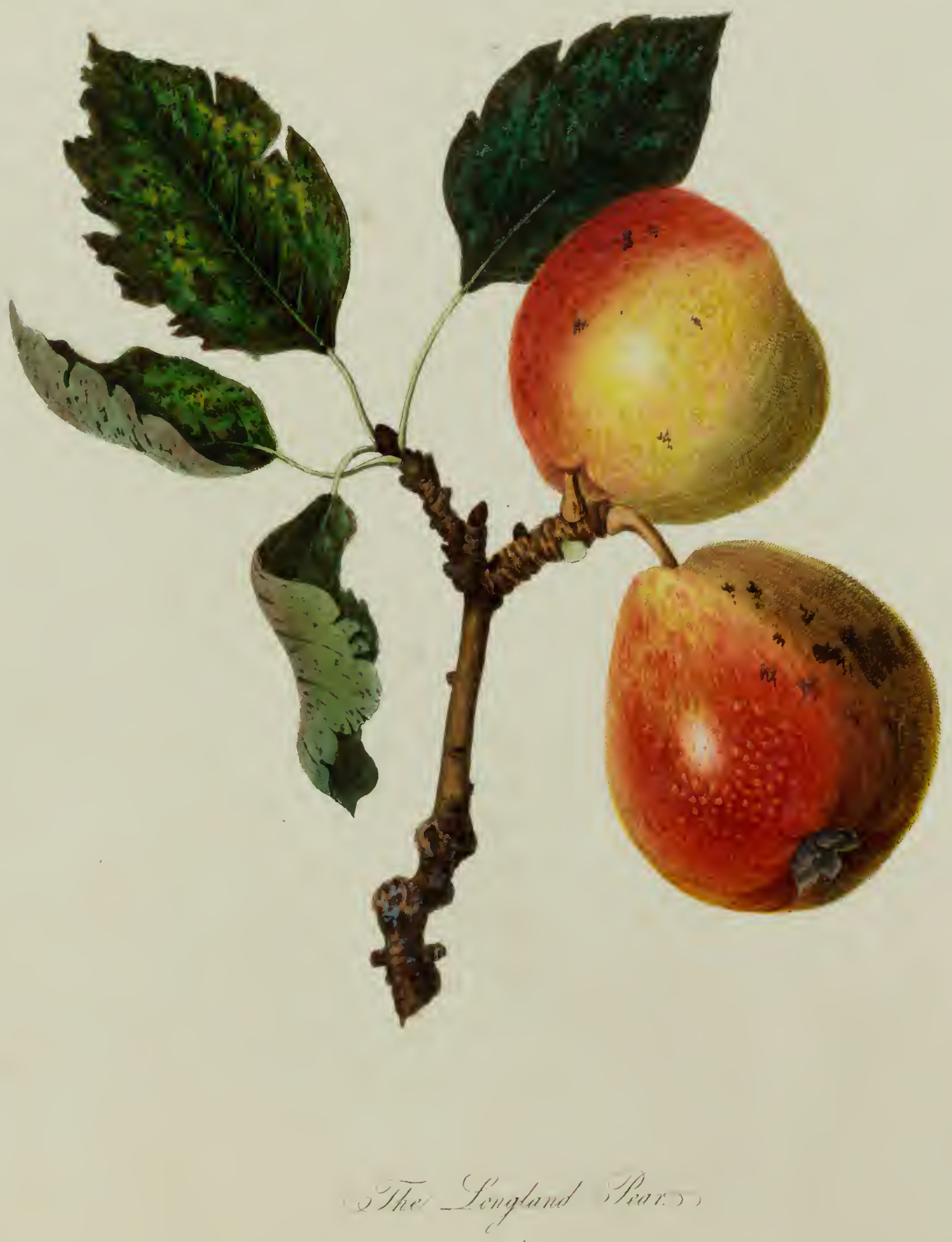




\section{XVIII.}

\section{THE LONGLAND PEAR.}

The perry which this pear produces is always without the fine flavour, which distinguishes some other varieties; but it is also generally free from the keen acid, which deducts much from the value of those kinds: and it much more nearly resembles cider, than any other kind of perry. It is consequently more valuable to the farmer for ordinary purposes, than any other; and its quality, compared with common ciders, is rarely much below mediocrity. Its blossoms are extremely patient of cold and unfavourable weather, and the trees are consequently very productive; but the variety appears to be rapidly approaching that period, when it can no longer be cultivated with advantage.

The specific gravity of its juice, expressed from a good sample of the fruit, I found to be 1063: it probably derived its name from the field, in which the original tree grew. 



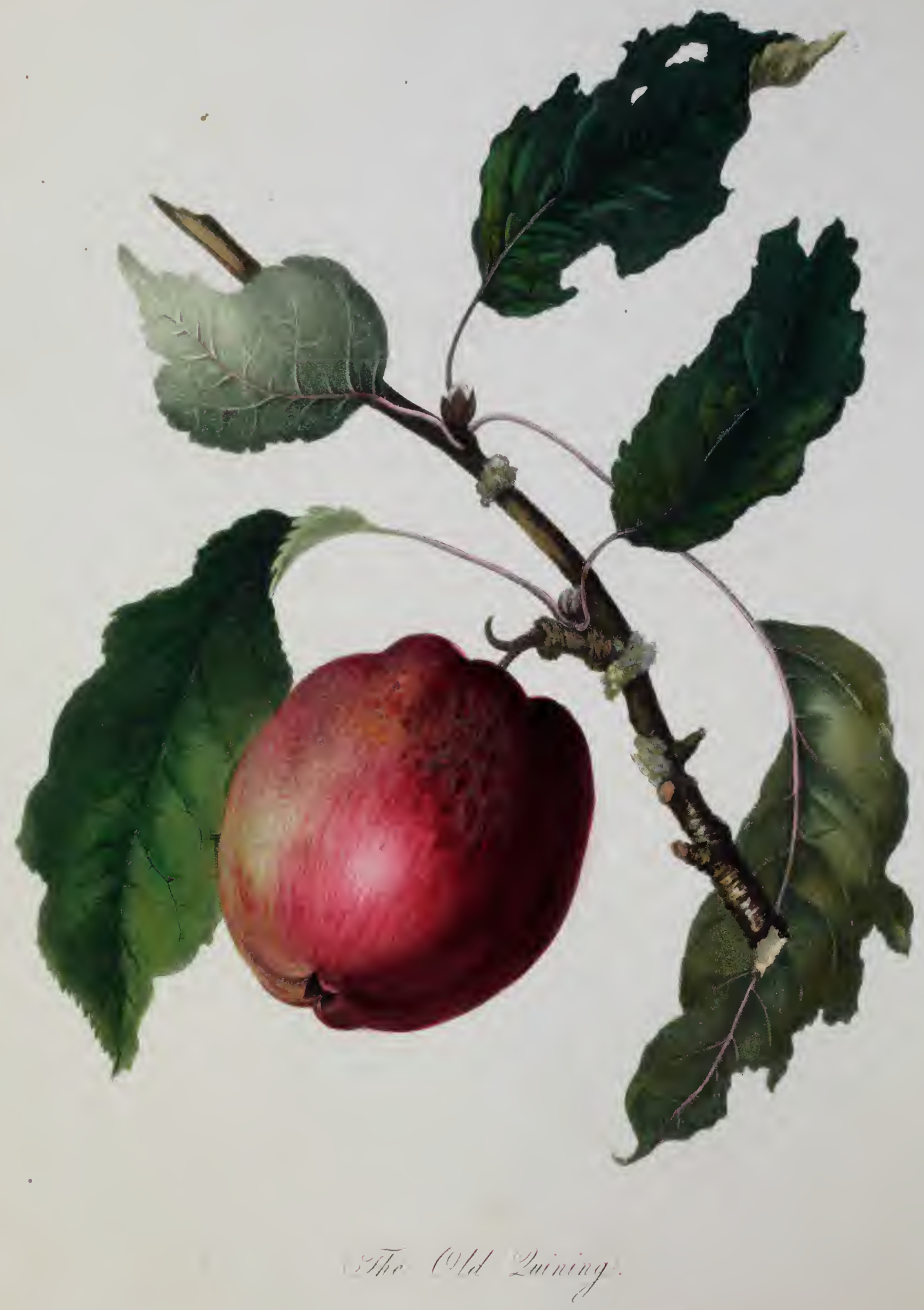


XIX.

\section{THE OLD QUINING.}

Many varieties of apples have been classed together under the name of Quining, in Herefordshire; it is a kind of generic name, including many species, all of which are distinguished by their angular shape, and generally by a very strong aromatic smell, and flavour. The apple which is delineated in the annexed plate possesses great excellence for the dessert, when first gathered from the tree; and it was highly estimated by the planters of the 17 th century, as a cider apple: but it is now in the last stage of decay: and like the Redstreak and Golden Pippin, has survived its good qualities for the press. This apple appears in some old Catalogues under the name of Queening; but it is always called Quining, and I believe the name rather to have been derived from Coin, an angle, than from Queen; and it is not improbably an imported variety. The specific gravity of its expressed juice is about 1073. 



XX.

\section{THE HOLMORE PEAR.}

A Pear, to be well calculated for the press, must possess a combination of properties, which will rarely be found in the same variety. It must contain much saccharine, and much astringent, matter, or its juice will become acetous; and if fine flavour be not united to strength and richness, the Perry will be of little value. Few varieties of the Pear are therefore known, which deserve the care of the planter, who cultivates for the press; and amongst several hundred seedling plants, of which I have examined the fruit, the Holmore Pear alone has appeared to me to be capable of affording fine Perry.

In flavour this variety more nearly resembles the Barland Pear, than any other, with which I am acquainted: but it is less harsh and astringent, and it ripens earlier, and more perfectly before it falls from the tree. The specific gravity of the juice is about 1066. The young grafted trees grow freely, and are abundantly productive of fruit.

The original tree stands, in a hedge, on the estate of Charles Cooke, Esq. of the Moor, in the parish of Holmore, near Hereford; and it appears to be about seventy or eighty years old. 




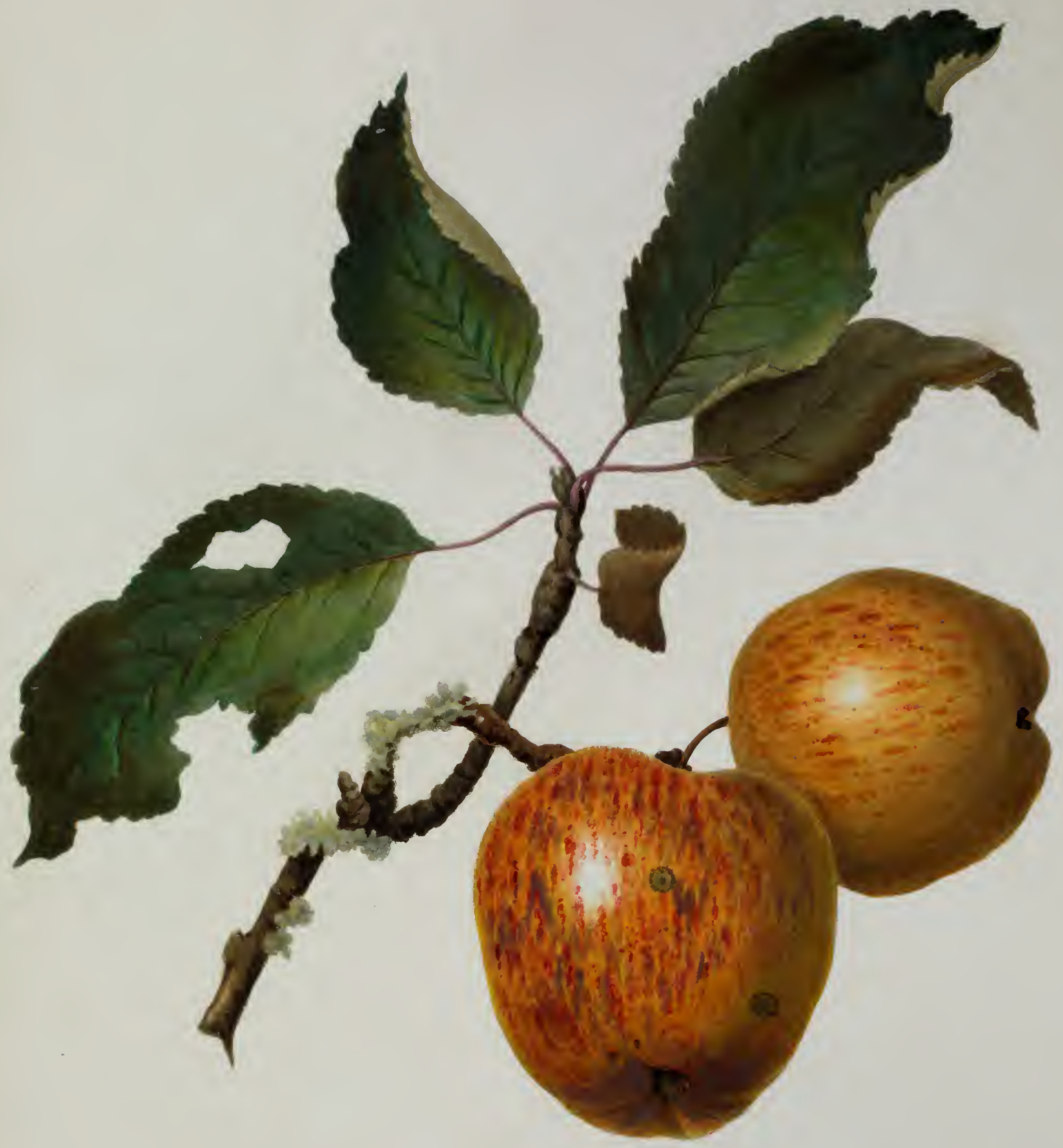

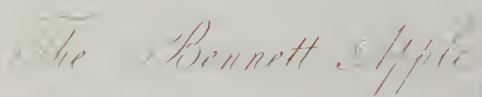




\section{XXI.}

\section{'THE BENNETT APPLE.}

The Bennett Apple has been chiefly cultivated in the deep and strong soils of the south-west part of Herefordshire, where, in conjunction with other varieties, it contributes to afford Ciders of great excellence. The bulk and obvious age of the trees prove this variety to have been known before the end of the 17 th century; though it is not mentioned (I believe) by any writer of that period.

The origin of the name is unknown; but it is probably derived from that of the person who first raised it from seed ; or from that of some other person, who was erroneously supposed to have improved it, by susbequent culture. The specific gravity of the juice is about 1073 . 




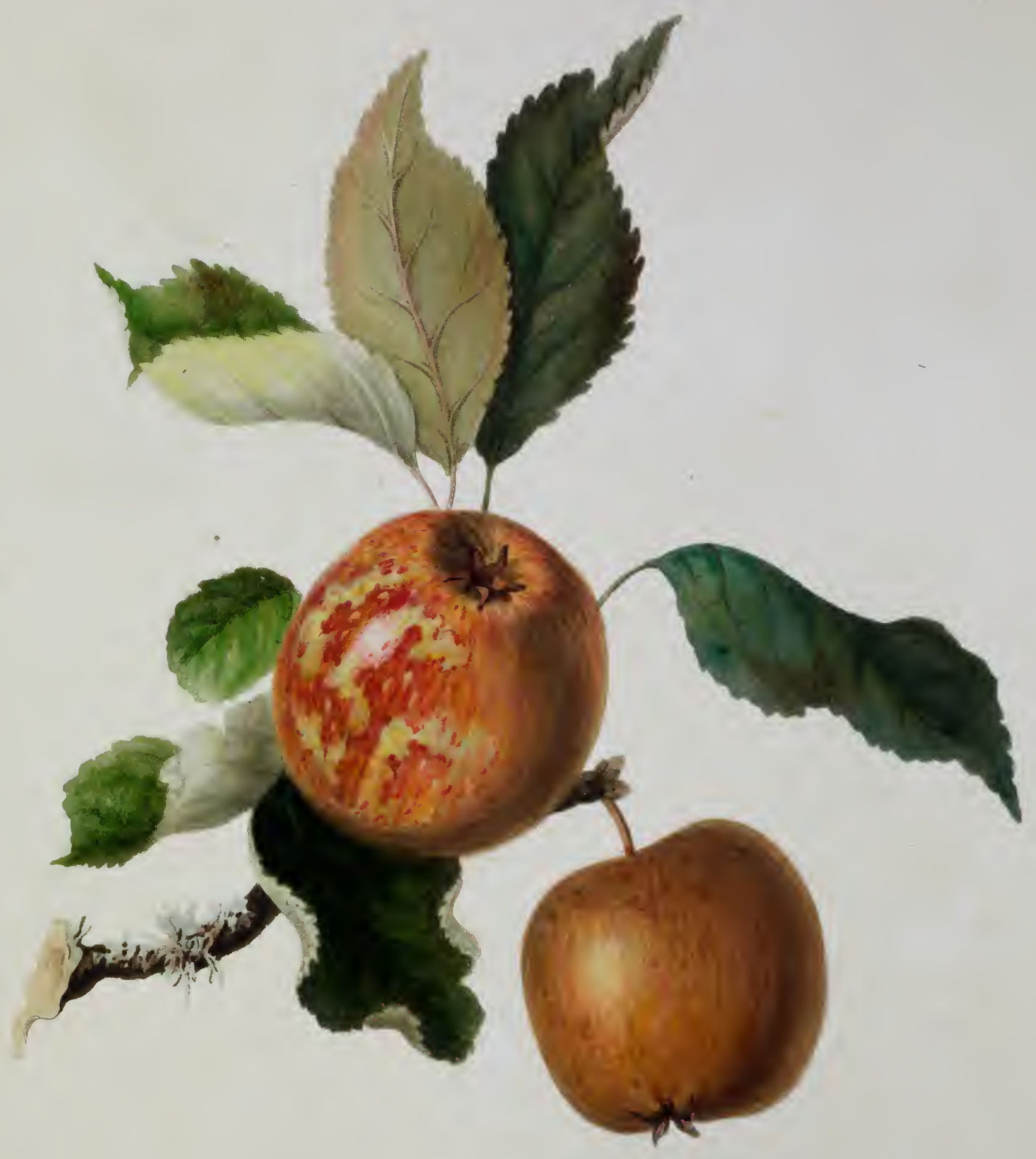

Whe Gelter. Henrury. 
XXII.

\section{THE GOLDEN HARVEY, OR BRANDY APPLE.}

Three different varieties of Apples are distinguished by the name of Harveys in Herefordshire, the Golden, the Russet, and the Scotched: of these the Golden alone, which has derived its name from the bright yellow colour of its pulp, is valued for the press. It is doubtful whether the writers on fruits of the 17th century, were acquainted with this Apple: though EVELYN states, that some persons preferred the Cider of the "Harvey Apple (being boiled)," to all other Ciders; and the Harvey Apple, and Russet Harvey, are both mentioned by Worlidge. For if the Golden Harvey had been known to WORLIDGE, its excellence for the dessert, would have caused it to be cultivaled in every part of England; and to be every where esteemed, as it is in Herefordshire, the best fruit of its species.

The Cider afforded by the Golden Harvey, generally possesses very great strength, with little richness; and it has been thence called the Brandy $A$ pple: in a very warm situation and season it, however, sometimes affords a most exceedingly rich and fine Cider. The fruit may be preserved for the dessert, in perfection, from December till May, and even later.

The trees of this variety still possess a considerable share of 
health and vigour; and for culture, in the garden only, it is not much impaired by age. The specific gravity of its juice, considerably exceeds that of any other Apple which I have yet had occasion to describe, bcing about 1085. 



$$
80
$$




\section{XXIII.}

\section{THE SIBERIAN HARVEY.}

This variety is the offspring of a seed of the yellow Siberian Crab, and the pollen of the Golden Harvey, and it derives its existence from a successful attempt to combine the hardy energetic character, and early maturity, of the Siberian Crab, with the disposition of the Golden Harrey to generate saccharine matter. Such an experiment cannot be expected very often to succeed; and of more than three hundred varieties of this family, which I have obtained from seeds, not more than three or four appear to possess any degree of merit; and the Siberian Harvey alone, will probably deserve a place in the orchard.

The juice of this variety is most intensely sweet, and is pro. bably very nearly what that of the Golden Harvey would be in a southern climate. 'The original tree produced its first blossoms in the year 1807, when its fruit obtained the annual premium of the Herefordshire Agricultural Society; and it has subsequently produced fruit every year: but the tree has been so closely pruned for grafts, that I have once only possessed fruit enough to enable me to subject the juice to the evidence of the hydrometer; and the sample of fruit I then obtained was apparently very unfavourable. The specific 
gravity of the juice, nevertheless, greatly exceeded that of any other varicty, being 1091; and it is therefore probable that this Apple will afford a richer Cider than any other at present known.

The fruit becomes perfectly ripe about the middle of $\mathrm{Oc}$ tober; but it will remain on the tree long after it is ripc, and after the leaves which surround it, on the bearing branches, have fallen. The drawing of this Apple was taken in the cold and wet season of 1809; and it is in consequence shewn rather below its usual size: in every other respect the representation is admirably correct. The blossoms of the Siberian Harvey appear to be extremely patient of cold; and the rariety will probably prove exuberantly productive of fruit: but, as it blossoms early, it is better calculated for moderately elevated situations, than for such as are low, and well sheltered. 



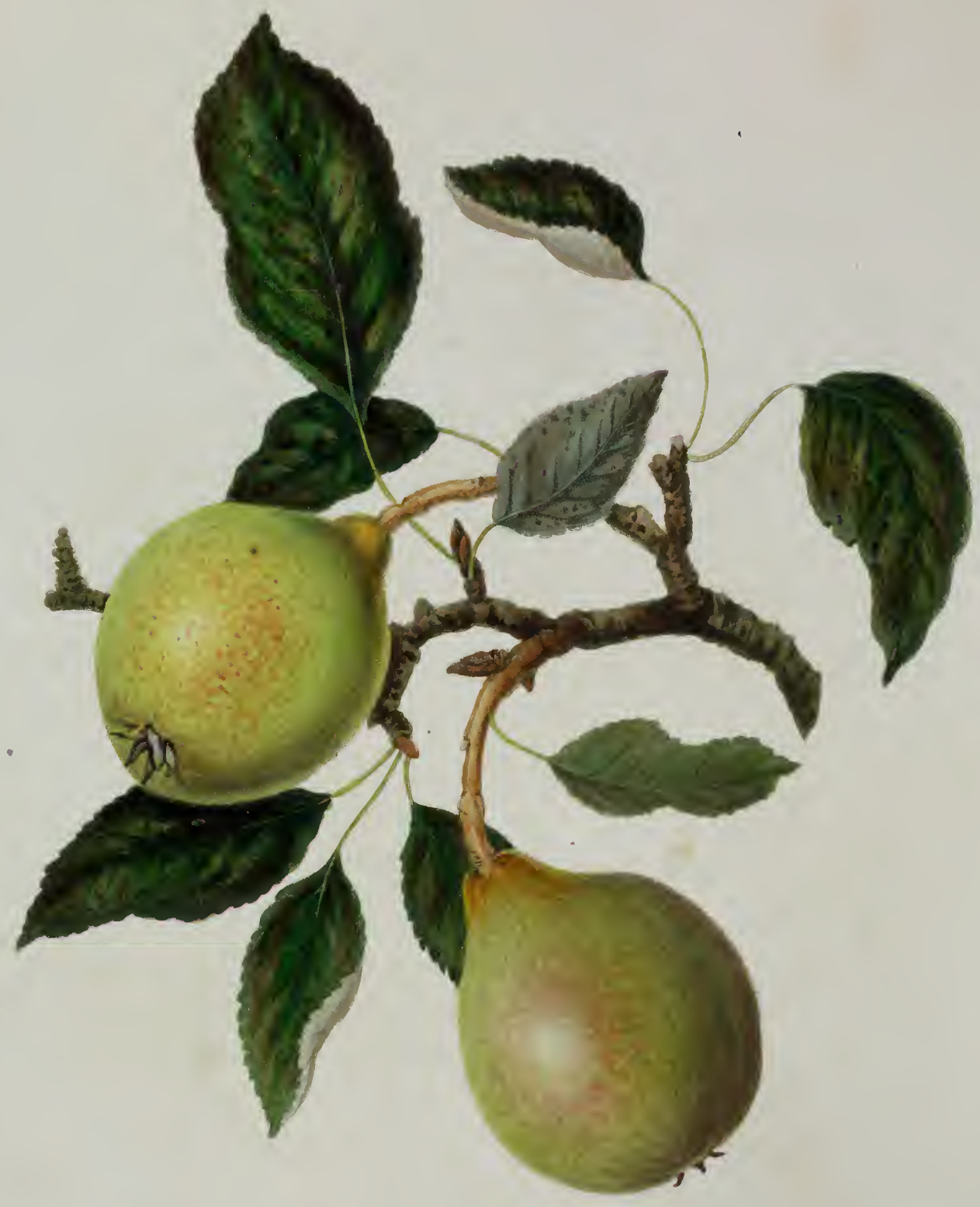

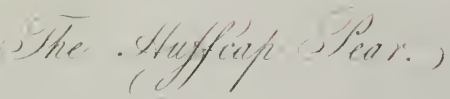




\section{XXIV. \\ THE HUFFCAP PEAR.}

So many distinct varieties of the Pear have been confounded under this name, in different parts of Herefordshire, that it would be difficult to prove, with certainty, which was the original: that represented in the Plate, however, seems to have much the best pretensions; and it affords Perry of the greatest excellence.

This Pear must have been known to the writers on orchards of the 17 th century; though the name does not occur in any of them: and it was probably one of the "Choke Pears," which they state to have abounded in Herefordshire at that period. The fruit is excessively harsh and austere; but its juice becomes very sweet during the process of grinding; and the Huffcap Perry possesses much strength and richness. In flavour also it is esteemed inferior to the 'Teinton Squash alone; and it has the credit of intoxicating more rapidly than any other Perry. I have not had an opportunity of ascertaining the specific gravity of the juice, which, I believe, would be found at least 1070 . 




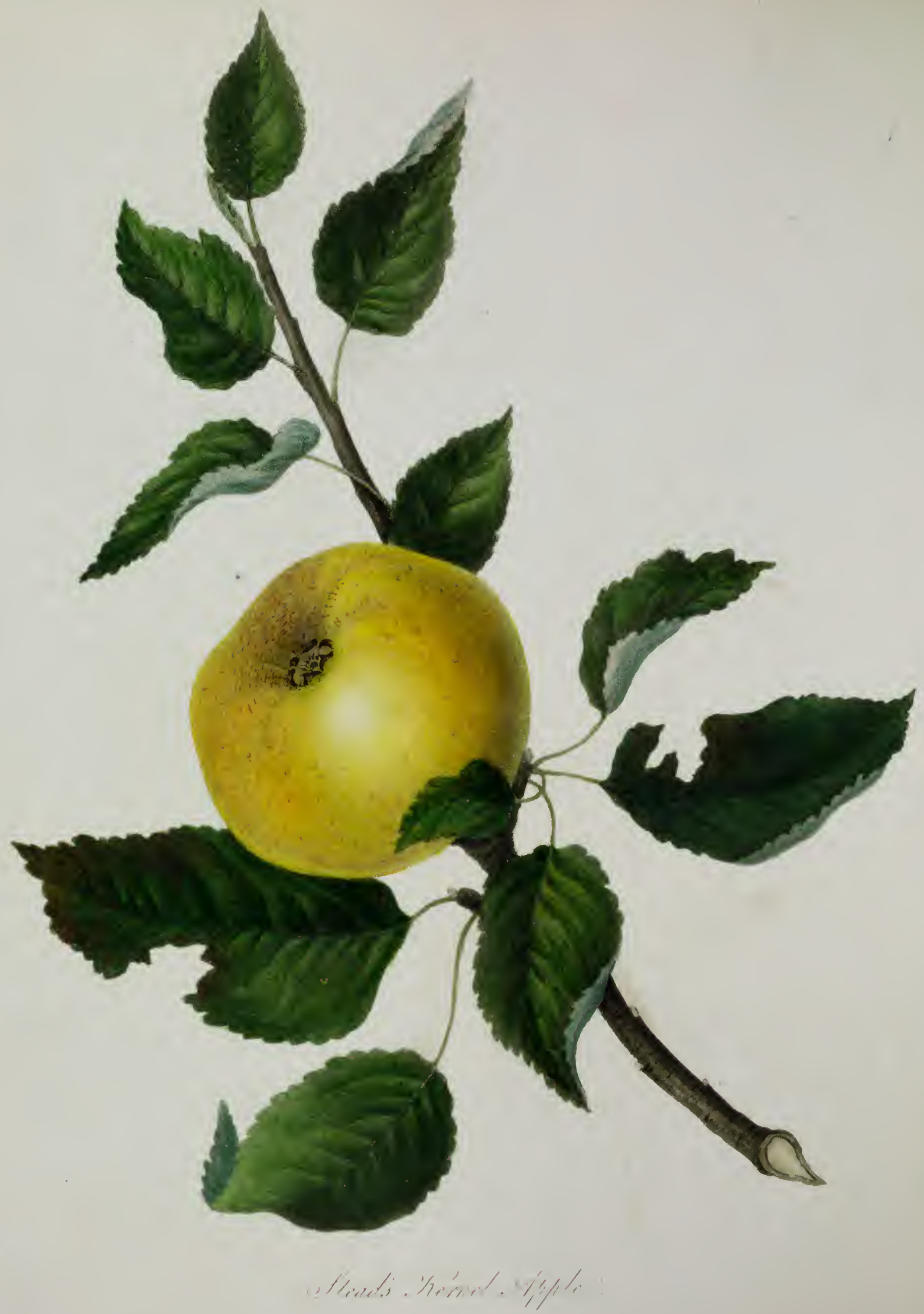




\section{$\mathrm{XXV}$.}

\section{STEAD'S KERNEL APPLE.}

This Apple received its name from that of the gentleman who raised it from seed; * and the original tree stands upon an estate, which he formerly possessed, and which is now the property of the Rev. Thomas Alban, at Brierly, near Leominster. It is not known from the seed of what Apple this variety sprang; and both the tree and fruit bear so little resemblance to any others, that no ground for conjecture is given. Many grafts have been taken from the original tree, which, in favourable soils and situations, grow and bear well : but this variety does not appear to be so hardy as some others. The branches are generally slender, and consequently pendant.

As a Cider Apple, it appears to possess great merit, combining a slight degree of astringency, with much sweetness; and it is an excellent Apple for every culinary purpose during its season. It ripens in October, and acquires a most perfect state of maturity long before it falls from the tree : it would well deserve a place in the desert, but that its pulp is somewhat tough and fibrous. The specific gravity of its juice is about 1074, and I have found little variation when the fruit has grown in different soils and situations.

\footnotetext{
* The late Danizl Stzad, Esq. of Broadward.
} 



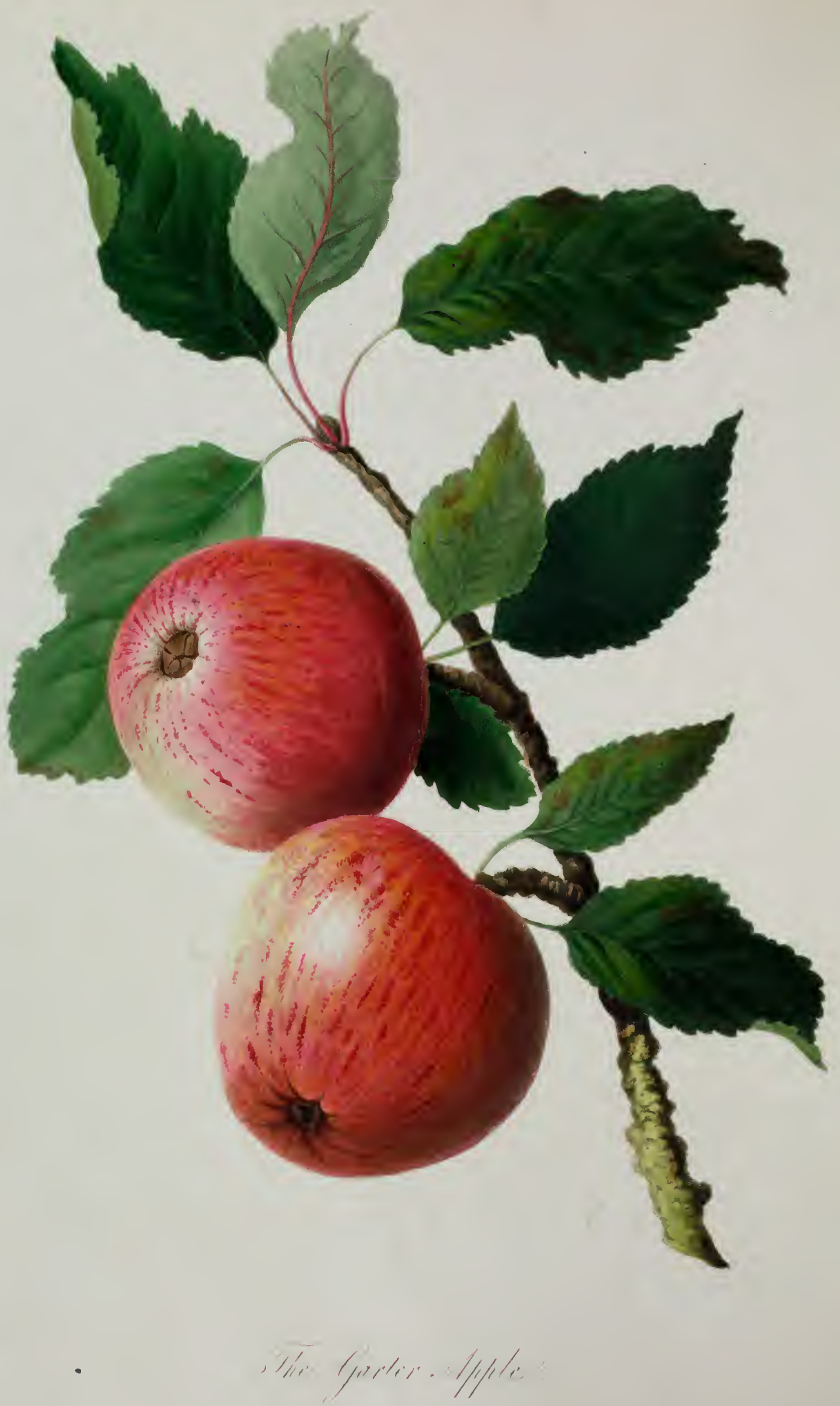


XXVI.

\title{
THE GARTER APPLE.
}

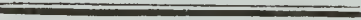

The Garter Apple has been much cultivated during the decay of the older and more valuable varieties; and in mixture with those, though it contains but a small portion of saccharine matter, it contributes to afford excellent ciders. It is not mentioned by any writer on orchards, with which I am acquainted.

The specific gravity of the juice, when obtained from a very favourable sample of the fruit, did not exceed 1066, and it was, in other instances, considerably lower.
\end{abstract}





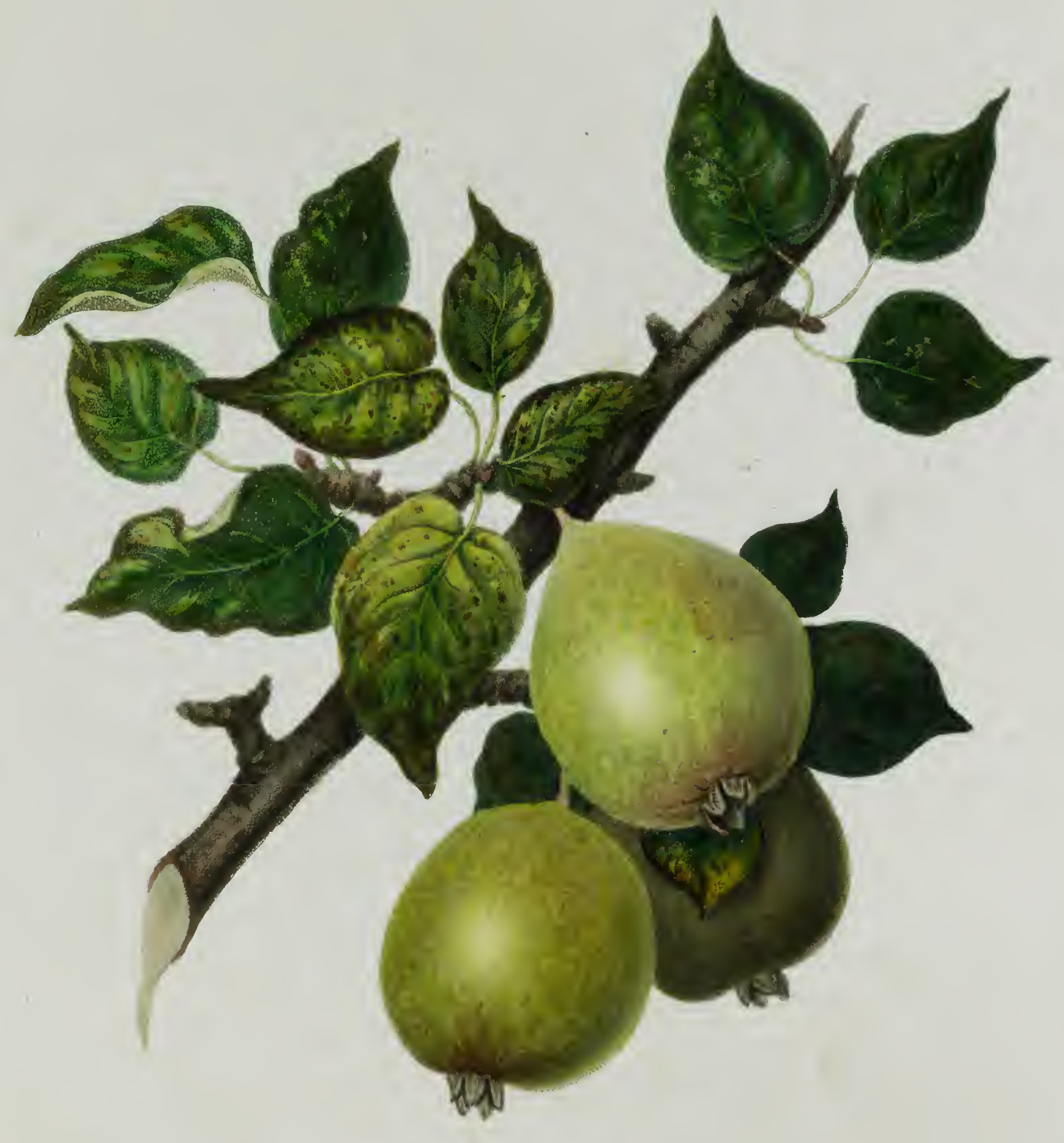

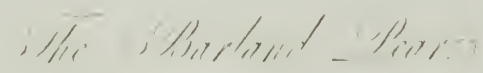




\section{XXVII.}

\section{THE BARLAND PEAR.}

The writers on orchards of the 17 th century, have expatiated widely upon the excellence of this pear, for the press; and it has, in consequence, been much planted in Herefordshire, and in some of the adjoining counties. Wherever the soil and climate have been favourable, the trees have acquired an extraordinary sizeand height; and they are much distinguished by the beauty of their forms and foliage.

Many thousand hogsheads of perry are made from this fruit, in a productive season; but the perry is not so much approved by the present, as it was by the original planters. It, however, sells well, whilst new, to the merchants; who have, probably, some means of employing it, with which the public are not acquainted: for $I$ have never met with it, more than once, within the last twenty years, out of the districts in which it is made, and many of the Herefordshire planters, have applied to me in vain, for information respecting its disappearance. It may be mingled in considerable quantity, with strong and new port, without its taste becoming perceptible; and as it is comparatively cheap, it possibly sometimes contributes one of the numerous ingredients of that popular compound. 
The Barland Pear appears to have been extensively cultivated in Herefordshire, prior to the publication of EvELYN's Pomona in 1674, in which it is very frequently mentioned; and as no trees of this variety are found in decay from age, in favourable soils, it must be concluded, that the identical trees, which were growing when EvELYN wrote, still remain in health and vigour.

The original tree grew in a ficld called the Bare Lands, whence the variety obtained its name, in the parish of Bosbury, and was blown down a few years ago. The specific gravity of the expressed juice, is about 1070. 



$$
8
$$


XXVIII.

THE COWARNE RED.

Though this Apple is greatly inferior to many of the older varieties, it has been, during the progressive decay of those, of much value to the Herefordshire Planters; for it has afforded very large and well formed trees, and an abundant produce of fruit. Its age cannot be accurately ascertained; but it does not occur in any old catalogue of fruit, and the growth, and vigour of the trees appear to indicate that scarcely more than a century has elapsed since it first sprang from seed. It is consequently still capable of being cultivated with success; but its merits are not nearly equal to those of several other varieties, which have recently been obtained from seed.

The specific gravity of the juice of the Cowarne Red, which I obtained from different soils and situations, never exceeded 1069. The variety derives its name from that of the parish in which it was first cultivated. 




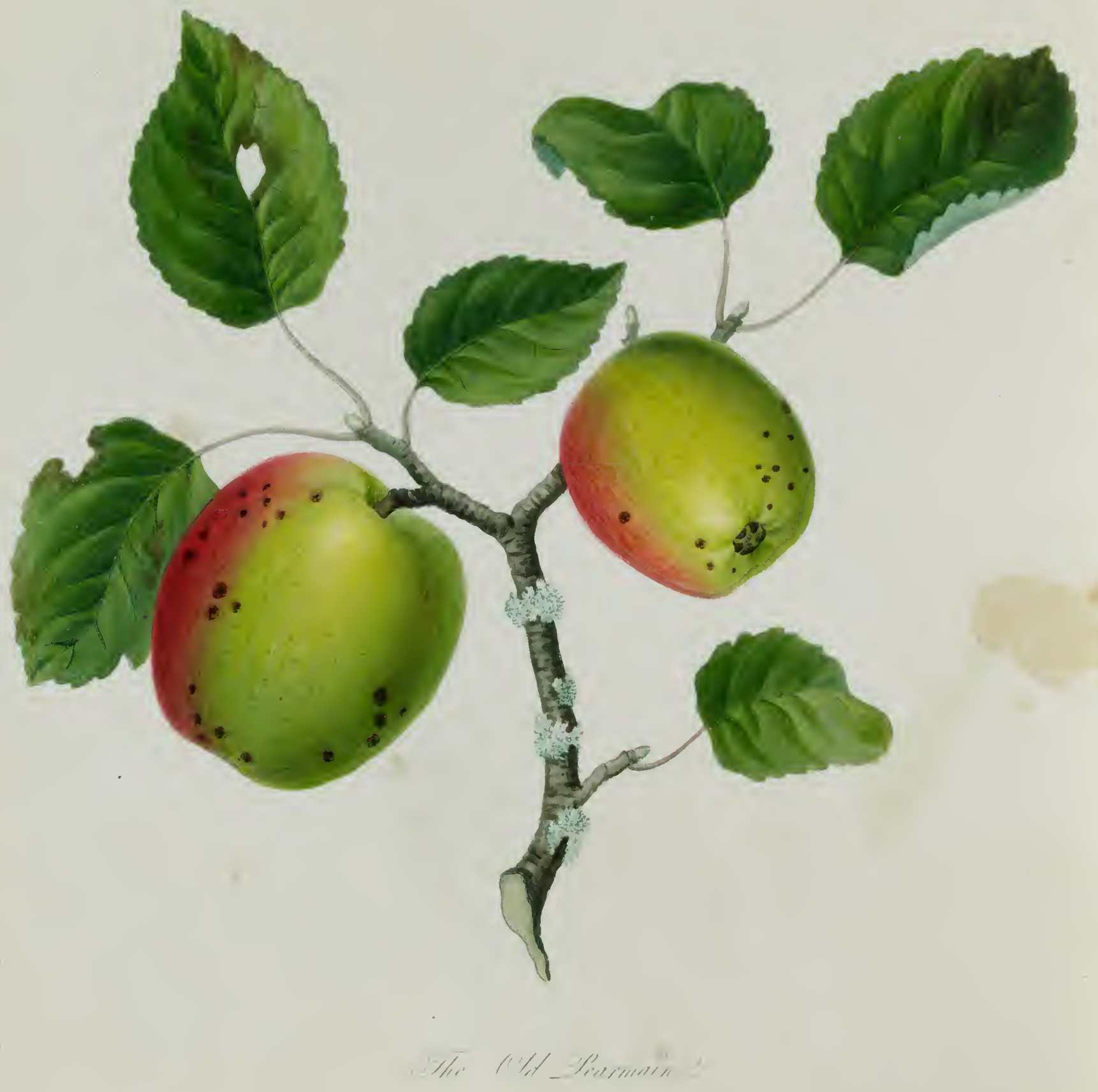


XXIX.

THE OLD PEARMAIN.

This variety appears to have been extensively cultivated early in the 17th century; and it occurs in Evelyn's Pomona, and Worlidge, and other writers of that period, under the name of the Winter Pearmain. It appears also to have been cultivated upon the Continent, and to be the Parmain d'Hyver, and "Pepin Parmain d'Angleterre" of Knoop's Pomologie. But it is not found in Du Hamel; and from this circumstance, and from the names given it by Knoop, it may be supposed to be an original English variety. It is an excellent Apple, and equally well calculated for the press or the dessert: but it has almost disappeared in the orchards of Herefordshire; and it was not without considerable difficulty that a proper specimen, for delineation, was procured in the last season.* The specific gravity of its juice is about 1079 .

In a light soil, and warm situation and season, the colours are more clear and bright, than the plate represents them; whence Philips has called it

The fair Pearmain,

"Tempered like comeliest nymph, with red and white."

* This variety has sometimes been confounded with the Green Pearmain, which it resembles in the greenness of its skin; but from which it differs in the yellowness of its pulp, in its smaller size, and much greater richness. 



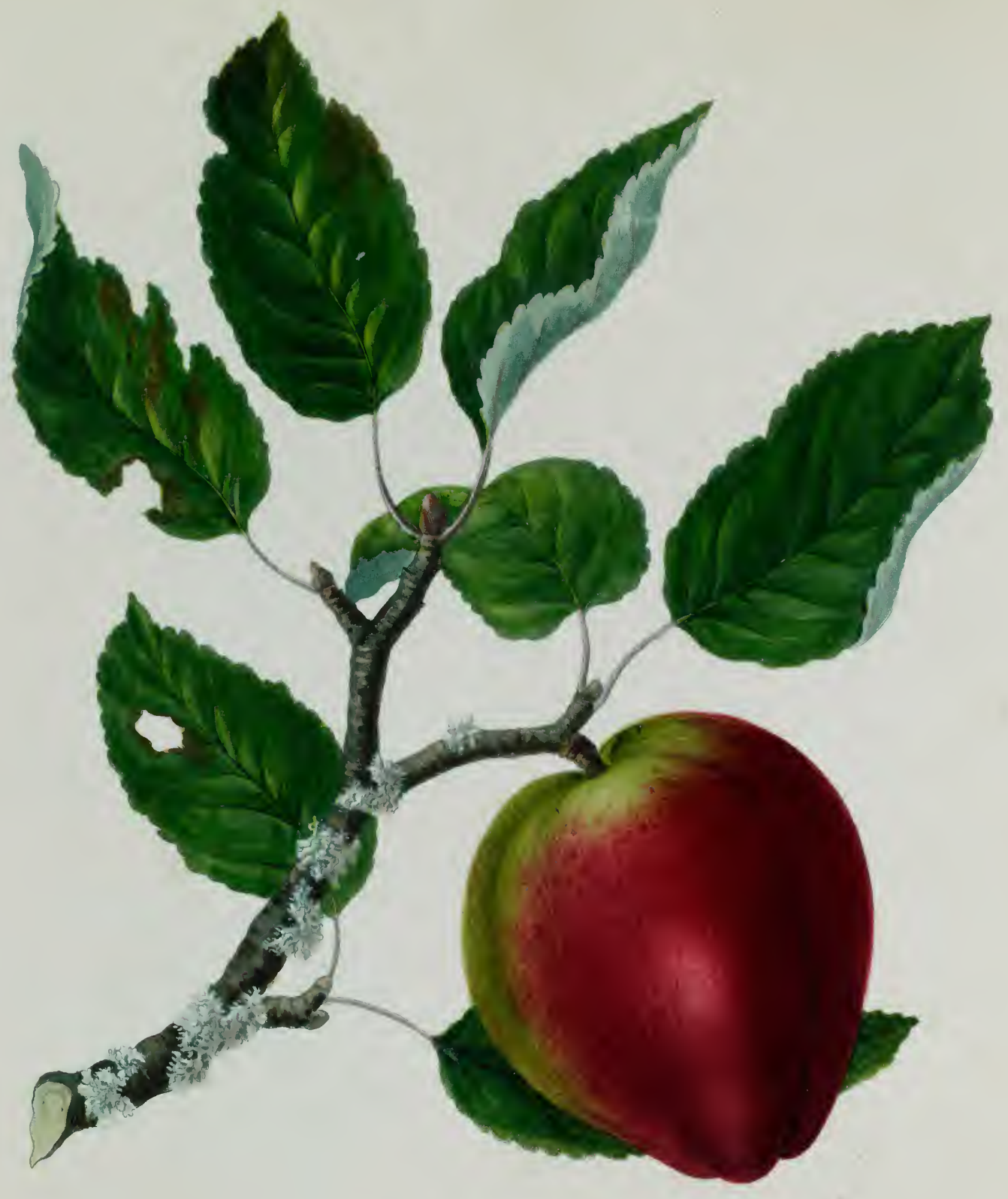

Whe , Herier. 
XXX.

THE FRIAR.

The culture of this Apple has been almost wholly confined to the north-west parts of Herefordshire; where the climate is cold, and the soil unfavourable; and where proper attention is never paid by the farmer, to the management of his Cider ; which in consequence is generally fit only for the ordinary purposes of a farm-house. But, under all these disadvantages, this Apple not unfrequently affords a cask of excellent Cider; and if it had been cultivated in a more favourable soil and climate, few Apples would have more amply repaid the care of the planter. It appears to be still capable of being cultivated with some advantage; for the trees are generally rigorous and productive; but some of them have stood at least a century, and therefore an orchard, now planted with it, would probably soon exhibit symptoms of the debility of old age.

The Friar probably derives its name from some imagined resemblance between its colour, and that of the countenance of a well fed ecclesiastic** The specific gravity of its juice, in the districe where it is chicfly planted, is about 1073; but under more favourable circumstances it would probably be several degrees higher.

* It is sometimes erroneously called the "Red Richard," with which variety it agrees in colour only. 




